\title{
Traditional and New methods for the Preparation of Diazocarbonyl Compounds
}

\author{
ANTONIO C.B. BURTOLOSO, PATRÍCIA B. MOMO and GRAZIELE L. NOVAIS \\ Instituto de Química de São Carlos, Universidade de São Paulo, Avenida João Dagnone, \\ 1100, Jardim Santa Angelina, 13560-970 São Carlos, SP, Brazil \\ Manuscript received on September 29, 2017; accepted for publication on November 16, 2017
}

\begin{abstract}
For many years diazocarbonyl compounds have been studied due to their versatility and usability in many chemical transformations. In this review, we summarize the traditional methods to prepare these compounds as well as the new methods and recent improvements in experimental procedures. Moreover, emergence of continuous flow techniques has allowed safer and environmentally friendly procedures for the handling of diazomethane and diazo compounds and will also be a topic in this review.
\end{abstract}

Key words: acylation, diazocarbonyl, diazocompounds, diazo transfer, synthetic methodology.

\section{INTRODUCTION}

Since the first time that diazocarbonyl compounds were reported by Curtius (Curtius 1883), the development of diazocarbonyl chemistry had an enormous advance. Thus, several publications with respect to the preparation, properties, and applications in organic chemistry have been published (Doyle et al. 1998, Ford et al. 2015, Maas 2009, Ye and McKervey 1994).

Diazocarbonyl compounds, containing two functional groups, "diazo and keto", are very versatile intermediates and can perform a number of chemical transformations. For example, these compounds can undergo $\mathrm{C}-\mathrm{H}$ and $\mathrm{C}-\mathrm{X}$

Correspondence to: Antonio Carlos Bender Burtoloso

E-mail: antonio@iqsc.usp.br

Patrícia Betoni Momo

E-mail: patriciabmomo@usp.br

* Contribution to the centenary of the Brazilian Academy of Sciences. insertion reactions, the Wolf rearrangement, cyclopropanations and dipolar cycloaddition (Figure 1) (Burtoloso et al. 2015). In addition, the use of diazocarbonyl compounds has showed significant developments in chemical biology such as the alkylation of DNA, RNA and proteins (Mix et al. 2016, Ford et al. 2015).

Common approaches to synthesizing diazocarbonyl compounds are: (a) acylation of diazoalkanes; (b) diazo transfer reaction; (c) diazotization of primary amines; (d) dehydrogenation of hydrozones; tosylhydrazones and oximes; (e) alkaline cleavage of $\mathrm{N}$-alkyl- $\mathrm{N}$ nitroso compounds; (f) triazene fragmentation (less common); (g) substitution and cross-coupling at diazomethyl carbon and; (h) substituent modification in diazocarbonyl compounds (Figure 2).

Therefore, our purpose in this review is to gather the classical methods of preparing 


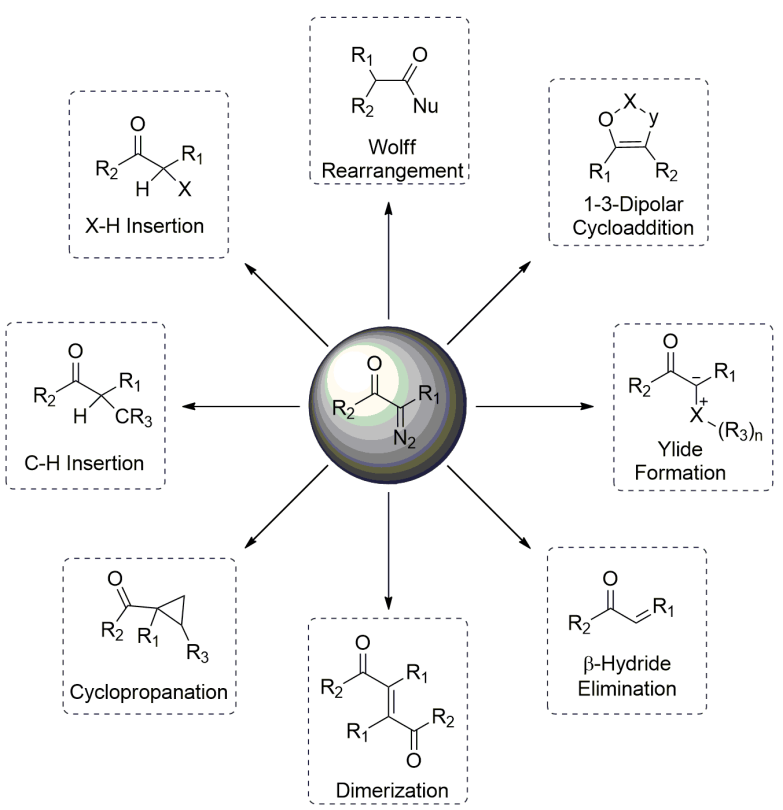

Figure 1 - Some reactions employing diazocarbonyl compounds.

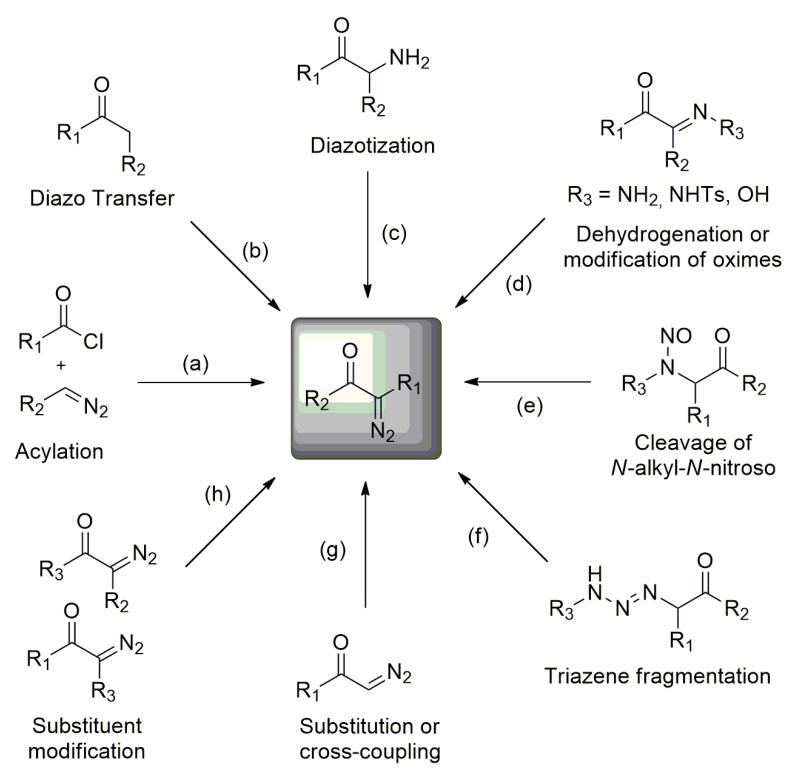

Figure 2 - Common methods to prepare diazocarbonyl compounds.

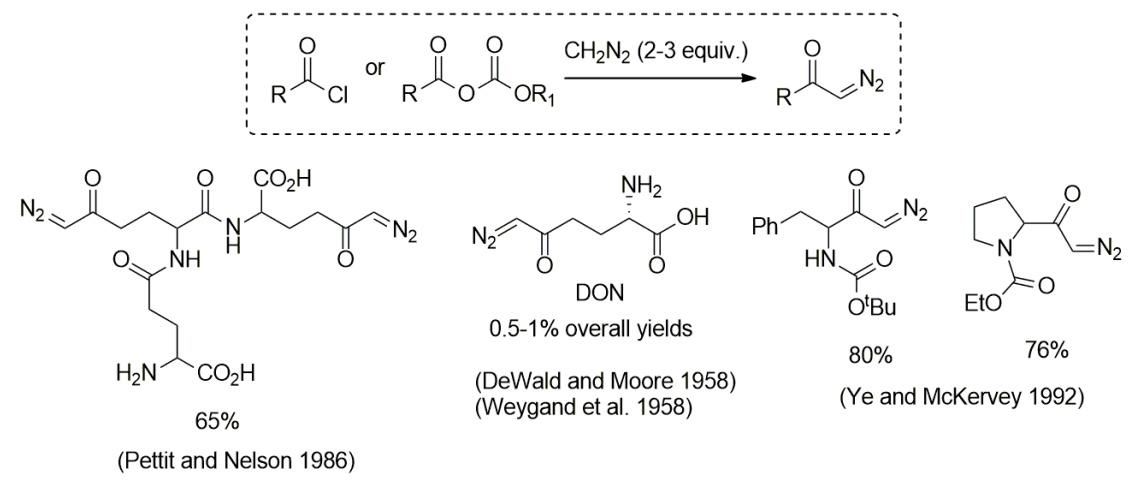

Figure 3 - Synthesis of terminal $\alpha$-diazocarbonyl compounds by acylation of diazomethane and some representative examples.

diazocarbonyl compounds and to describe the main recent improvements and developments in the synthesis of these compounds.

\section{CLASSICAL METHODOLOGIES FOR THE SYNTHESIS OF DIAZOCARBONYL COMPOUNDS}

\section{ACYLATION OF DIAZOALKANES}

The first general protocol to prepare terminal $\alpha$-diazocarbonyl compounds was described by Arndt-Eistert in 1927 (Arndt et al. 1927, 1928,
Arndt and Amend 1928). This method consisted in the addition of an acyl chloride to an ethereal diazomethane solution (2 equiv. or more) at or below $0{ }^{\circ} \mathrm{C}$ (Figure 3 ). In the Arndt-Eistert reactions, the use of excess of diazomethane is necessary to prevent the formation of chloroketones as a byproduct. This side reaction can be avoided using triethylamine or similar bases in the diazomethane solution when non-enolizable acyl chlorides are employed (enolizable precursors give lower yields of the diazoketone because of competing 


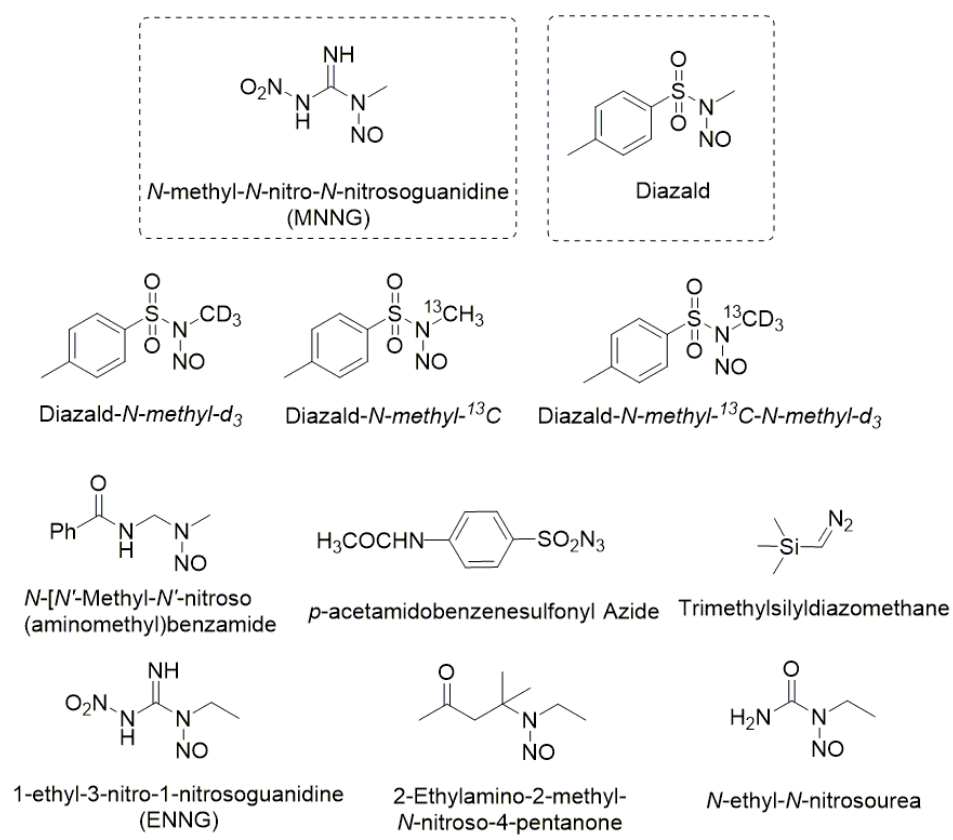

Figure 4 - Commercially available diazomethane precursors and other related compounds.

ketene formation). For this condition (base and non-enolizable acyl chlorides), only one equiv. of diazomethane is necessary.

Another procedure involves the use of mixed anhydrides as acylating agents of diazomethane (Bradley and Robinson 1928) (Figure 3). In this case, a convenient procedure prepares the anhydride by treating a carboxylic acid with dicyclohexylcarbodiimide and then reacting with diazomethane (Hodson et al. 1970). Mixed anhydrides can also be formed in situ by reaction between a carboxylic acid and chloroformates, leading to diazoketones after reaction with diazomethane (Ye and McKervey 1992). These methods, employing anhydrides, are the best choice to prepare several diazoketones when activation as acid chloride is not appropriate. Acylation of diazomethane using both acyl chlorides or mixed anhydrides remains as the most important approach to prepare acyclic terminal $\alpha$-diazoketones.

Although quite a lot of diazoketones can be made by the acylation method, working with pure diazomethane is hazardous, since it is extremely toxic, highly irritating as well as an explosive gas (NIOSH 1995). In addition, diazomethane and its precursors have been cited as carcinogens. However, these risks can be minimized using the proper apparatus and a dilute solution of diazomethane in ethyl ether at low temperatures. Diazomethane kits with clear-seal joints are commercially available and permits the preparation of diazomethane solutions in different scales $(1 \mathrm{mmol}$ to $0.3 \mathrm{~mol}$ quantities) (Sigma-Aldrich AL-180, Hudlicky 1980, 1982). The classical method of generating diazomethane is by base-catalyzed decomposition of an $N$-nitroso derivative from ureas, carbamates, sulfonamides and ketones (Figure 4). $N$-methyl$N$-nitroso-p-toluenosulfonamide (Diazald) is the most common precursor for diazomethane generation (de Boer and Backer 1963). However, the use of trimethylsilyldiazomethane has been a safer alternative for ethereal diazomethane solution (Shioiri et al. 1990). 


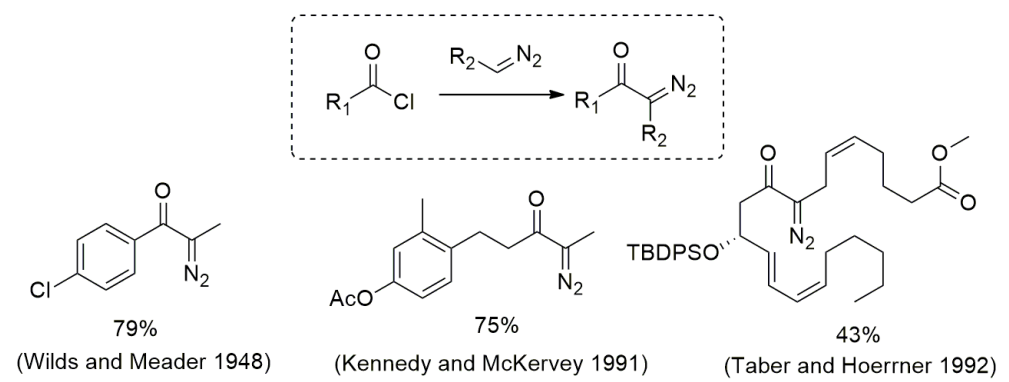

Figure 5 - Synthesis of unsaturated diazoketones by diazomethane acylation.

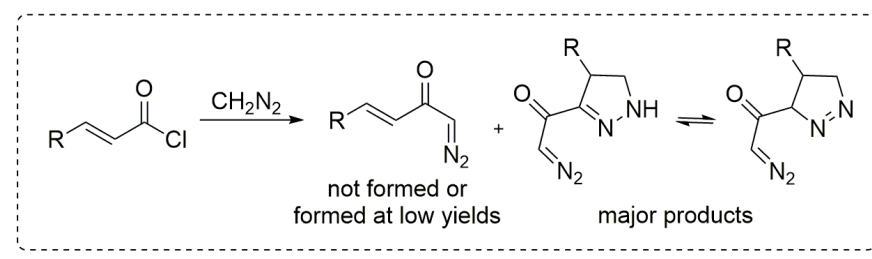

(Wotiz and Buco 1955)

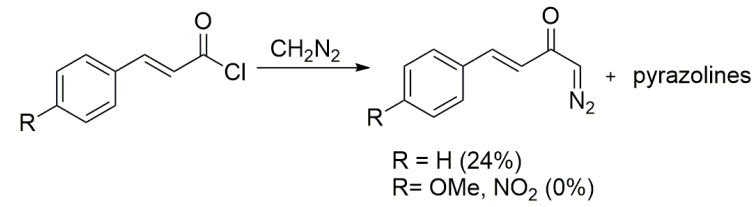

(Rosenquist and Chapman 1976)

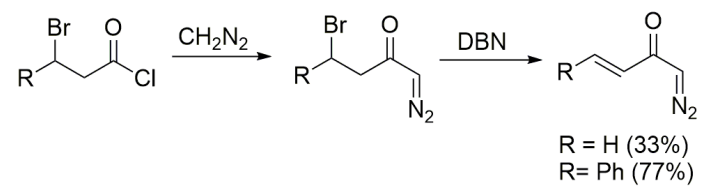

Figure 6 - Some synthetics intermediates obtained by acylation of higher diazoalkanes.

Acylation of diazoethane or other higher dizaoalkanes with acyl chlorides and mixed carboxylic anhydrides have been used to obtain numerous intermediates in synthesis (Wilds and Meader 1948, Kennedy and McKervey 1991, Taber and Hoerrner 1992) (Figure 5). However, these reactions usually are less efficient than using diazomethane. Diazoethane can be prepared from commercially available precursors as 1-ethyl-3nitro-1-nitrosoguanidine, 2-ethylamino-methyl$N$-nitroso-4-pentanone and $N$-ethyl- $N$-nitrosourea (Figure 3) (Doyle et al. 1998).

Diazomethane acylation has some limitations. This method is not suitable to $\alpha, \beta$-unsaturated substrates because dipolar cycloaddtion between diazomethane and the conjugated double bond often occurs. In these reactions, pyrazolines are obtained as the main product and unsaturated diazoketone are formed in poor yield (Grundmann 1936, Wotiz and Buco 1955). The formation of pyrazolines can be avoided by employing $\beta$-bromo acid chlorides that, after elimination, provides the desired unsaturated diazoketones (Rosenquist and Chapman 1976) (Figure 6).

In view of the limited scope of unsaturated diazoketones that can be obtained by acylation of diazomethane, Burtoloso's group have developed an alternative method to prepare these 


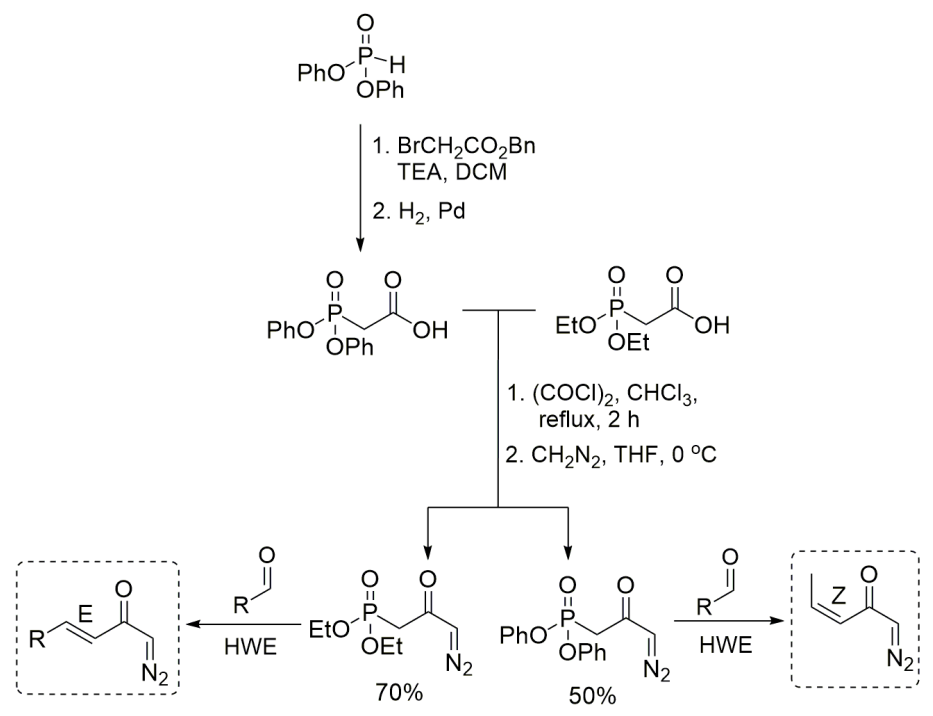

Figure 7 - Burtoloso's synthesis of $Z$ and $E \alpha, \beta$-unsaturated diazoketones.

compounds based on two Horner-WadsworthEmmons (HWE) reagents (Pinho and Burtoloso 2011, Rosset and Burtoloso 2013). One of them, diethyl 3-diazo-2-oxopropylphosphonate, was selective for unsaturated diazoketones with $E$ geometries while the other, diphenyl (3-diazo-2oxopropyl)phosphonate (Ando-type phosphonate), was selective for $Z$ geometries. These HWE reagents were prepared from the corresponding phosphorylacetic acids by reaction with oxalyl chloride and diazomethane in 50 and $70 \%$ yield, respectively (Pinho and Burtoloso 2011, Rosset and Burtoloso 2013) (Figure 7).

Both olefination reagents are stable and can be storaged for months as they begin to decompose only at temperatures above $120{ }^{\circ} \mathrm{C}$ ( $E$ HWE reagent) and $150{ }^{\circ} \mathrm{C}$ ( $Z$ HWE reagent) (Rosset and Burtoloso 2013). The HWE reactions with diethyl (3-diazo-2-oxopropyl)phosphonate and aldehydes furnished good results using $\mathrm{NaH}$ or $\mathrm{NaOH}$ as base. Complete $E$ selectivity was observed for all unsaturated diazoketone synthesized. Moreover, no epimerization at the $\gamma$-position was detected in the reactions using chiral amino-aldehydes (Burtoloso et al. 2015, Pinho and Burtoloso 2011). The high selectivity was also obtained in reactions with diphenyl (3-diazo-2-oxopropyl)phosphonate employing tert-butoxide as the base. However, the HWE reactions using amino aldehydes gave different stereoselectivities depending on the used nitrogen protecting group (Boc, $\mathrm{CBz}$ or Ts groups) as well as the size of the substituent at the $\alpha$-carbon to the carbonyl group (Rosset and Burtoloso 2013). Several $\alpha, \beta$-unsaturated $\alpha$-diazoketones with $Z$ and $E$ geometries were additionally prepared by Burtoloso's methodology (Bernardim et al. 2012, 2013, Bernardim and Burtoloso 2014, Rosset et al. 2014, Dias et al. 2017) (Figure 8).

Traditional ways of carboxylic acid activation (as an acyl chloride or mixed anhydride) can sometimes be difficult when hindered carboxylic acids needs to be converted to $\alpha$-diazoketones. Nicolaou and co-workers solved this problem employing acyl mesylates as intermediates for the synthesis of highly hindered $\alpha$-diazoketones (Nicolaou et al. 1999) (Figure 9).

Another different activation method was described by Cuevas-Yañez in which an acylphosphonium salt (generated from the addition of NBS to a mixture of triphenylphosphine and carboxylic acids, reacted with diazomethane to yield diazoketones in good yields (Figure 10). In 
<smiles>N#CC(=O)/C=C/c1ccccc1</smiles>

$78-91 \%$<smiles></smiles><smiles>N#CC(=O)/C=C/c1ccc(Cl)cc1</smiles><smiles>[R16]c1ccc(/C=C/C(=O)C=[W])cc1</smiles><smiles>N#CC(=O)/C=C/c1cccnc1</smiles><smiles>O=C(/C=C/c1ccco1)N=[W]</smiles><smiles>CCC/C=C/C(=O)/C=N\C([14CH3])=O</smiles>

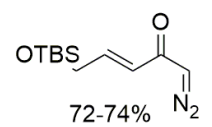<smiles>CC(C)CC([18OH])/C=C/C(=O)C=[W]</smiles>

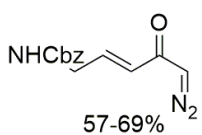<smiles>O=C(/C=N\[N+](=O)[O-])/C=C/C1CCNC1</smiles><smiles></smiles><smiles>CC(C)/C=C/C(=O)C=[W]</smiles><smiles>CCCCCCCCC/C=C/C(=O)C=N</smiles>

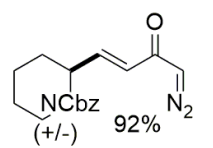<smiles>N=CC(=O)/C=C\c1ccccc1</smiles>

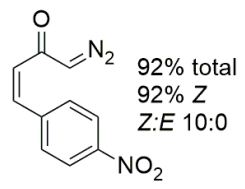<smiles>COc1ccc(/C=C\C(=O)C=N)cc1</smiles><smiles>CCCCC/C=C\C(=O)C=[W]</smiles>
$87 \%$ total Z.E 9.1

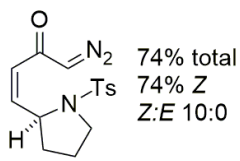

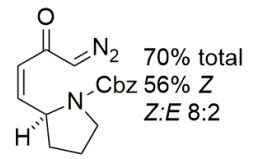

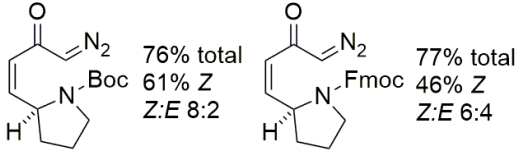

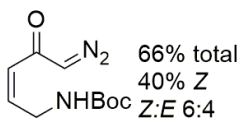

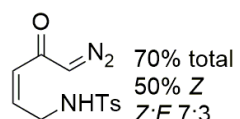

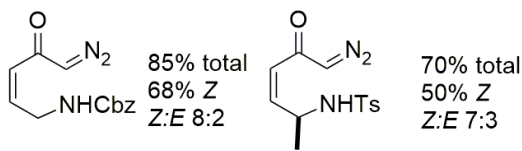

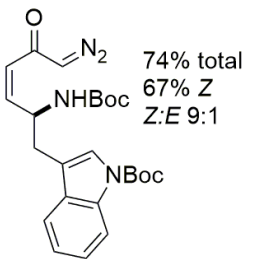

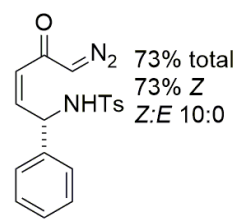

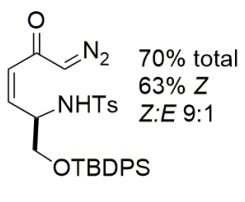

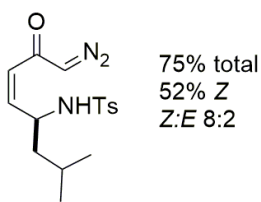

Figure 8 - Examples of $Z$ and $E \alpha, \beta$-unsaturated diazoketones prepared by Burtoloso's methodology.

addition, this method tolerated the use of various functional groups and the reactions were performed in mild conditions (Cuevas-Yañez et al. 2003).

As mentioned before, in the majority of the cases, it is necessary to employ an excess of diazomethane for the conversion of acyl chlorides to diazoketones to trap the hydrogen chloride byproduct. On this matter, Pace and co-workers have showed the synthesis of diazoketones using a stoichiometric amount of diazomethane in the presence of calcium oxide as a hydrogen halide scavenger, without competing ketene or haloketone formation (Pace et al. 2010) (Figure 11).

In the case of the preparation of $\alpha$-amino acidderived diazoketones, protection of the amino group before diazomethane acylation is necessary. Liguori and co-workers demonstrated the use of [(fluorenylmethyl)oxy]carbonyl chloride (Fmoc$\mathrm{Cl}$ ) as an effective reagent for the one-pot protection and activation of amino acids and subsequent conversion to $\alpha$-amino diazoketones (Siciliano et al. 2012) (Figure 12). 


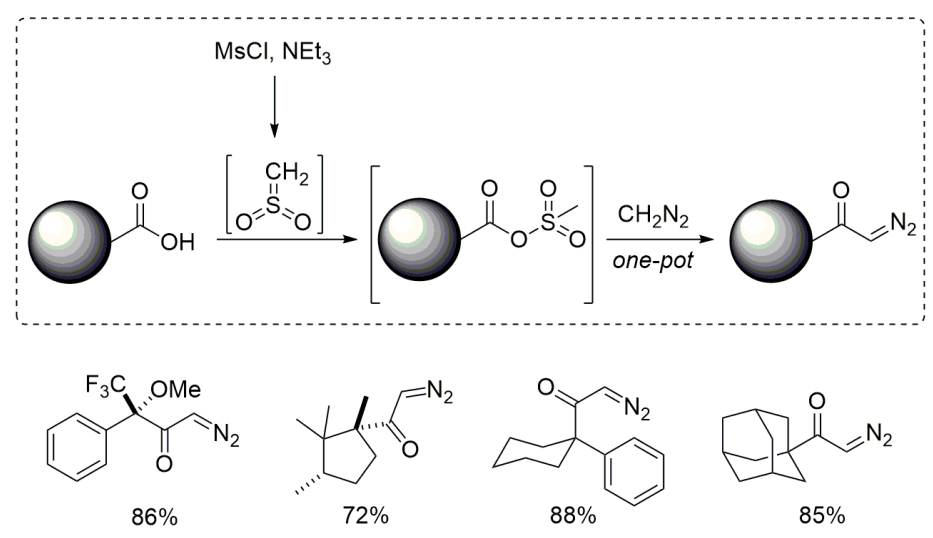

Figure 9 - Synthesis of highly hindered diazoketone by Nicolaou and coworkers.

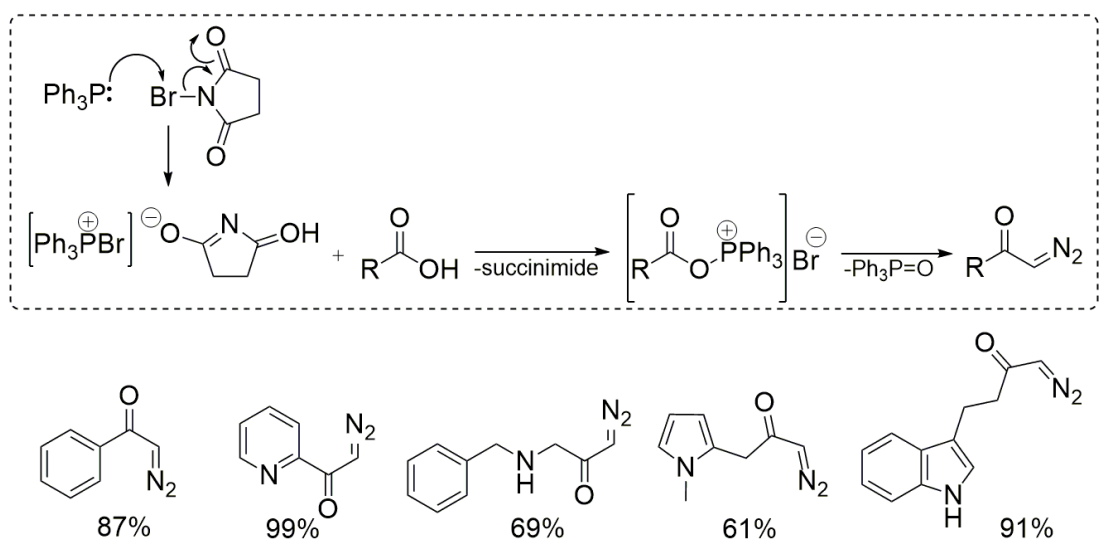

Figure 10 - Synthesis of diazoketones from acyloxyphosphonium salts and diazomethane.

Although many new ways of activating a carboxylic acid, aiming the synthesis of diazoketones were described the major improvements in the acylation methodology refers to the safe preparation of diazomethane. Morandi and Carreira developed an in situ generation of diazomethane using a water-soluble derivative of Diazald in a biphasic system (Morandi and Carreira 2012). In this work, the diazomethane was generated in the aqueous layer (in a 6 molar potassium hydroxide (KOH) solution) and transferred to an organic layer where an iron porphyrin complex catalyzed the cyclopropanation of styrene, enynes and dienes (Morandi and Carreira 2012) (Figure 13).
In addition, several researchers have explored the generation of diazomethane (and its use) in microreactors and in a continuous process. This minimize the hazard in handling diazomethane, as well as increase the safety in its use on an industrial scale (Müller and Wirth 2015, Gutmann et al. 2015). A simple flow process for diazomethane generation was developed by Struempel and Maggini (Struempel et al. 2008, Rossi et al. 2012). The system included a feed containing $\mathrm{N}$-methyl- $\mathrm{N}$-nitrosourea (MNU) or Diazald as a diazomethane precursor and another feed with potassium hydroxide solution. Both were combined in a microreactor to generate diazomethane and were mixed with substrate to yield the subsequent product (Figure 14). Despite this approach to be 


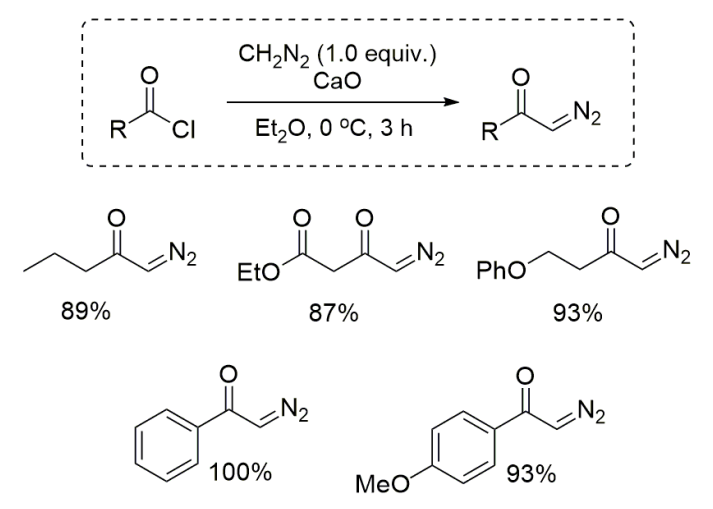

Figure 11 - Improved Arndt-Eistert synthesis of $\alpha$-diazoketones by Pace and co-workers.
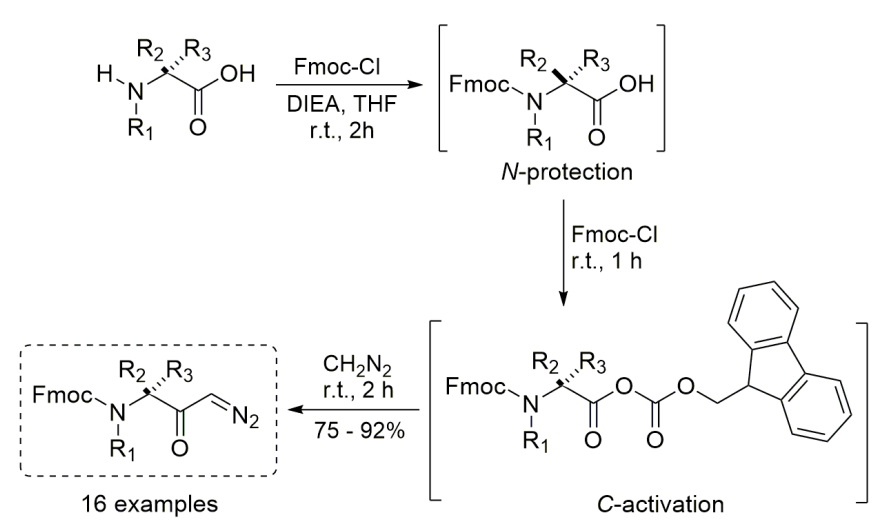

Figure 12 - The "one-step" route to the synthesis of $\alpha$-amino diazoketones published by Siciliano and co-workers.

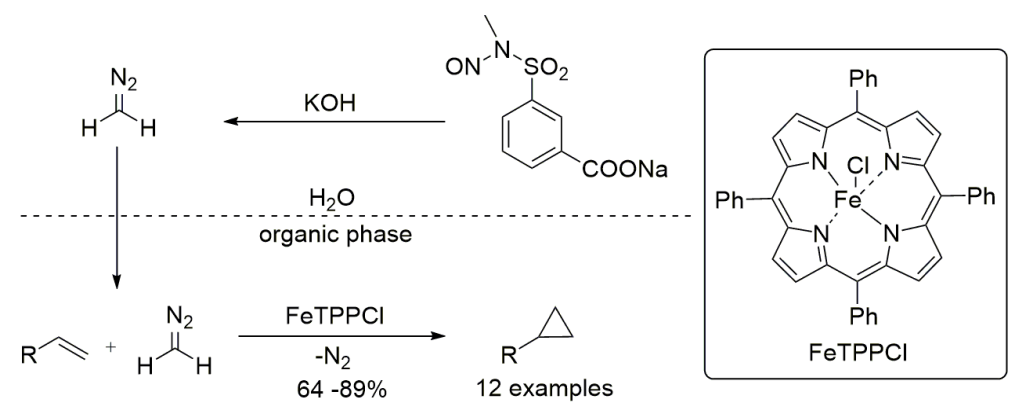

Figure 13 - In situ diazomethane formation and cypropanation in a biphasic system proposed by Morandi and Carreira.

effective for alkylation of carboxylic acids, an excess of the acid is essential to neutralize the base. In addition, it is not suited to reactions in which the starting material is water sensitive. A solution to this problem was proposed by Kim and co-workers who developed a microreactor with two parallel channels separated by a highly hydrophobic poly(dimethylsiloxane) (PDMS) membrane that allowed the separation of diazomethane from the aqueous solution of Diazald (Maurya et al. 2011) (Figure 14). However, this approach presented some limitations such as the small scale and the impossibility of using some non-polar organic solvents, as this could cause a swelling of the membrane.

The two limitations presented by PDMS membrane cited above have been overcome by Kappe and co-workers using the tube-in-tube (TiT) reactor AF-2400 which was initially developed in the Steven Ley laboratory (Mastronardi et al. 2013, Polyzos et al. 2011). The Teflon AF-2400 is a semipermeable membrane that allows only the passage of gases. Thus, diazomethane could be generated in the inner tube-in-tube reactor from an aqueous solution of Diazald and potassium hydroxide, while the substrate solution could be carried and reacted in the outer chamber. With this approach, it was possible to safely conduct the Arndt-Eistert reaction for the synthesis of diazoketones in a continuous process. Moreover, the setup was extended to achieve the direct transformation of protected $\alpha$-amino acids into the corresponding $\alpha$-chloroketones or $\beta$-amino acids in a continuous multistep reaction (Pinho et al. 2014a, b) (Figure 15).

The tube-in-tube reactor with semipermeable Teflon AF-2400 was also used in a simple and robust semi batch apparatus for the in situ 


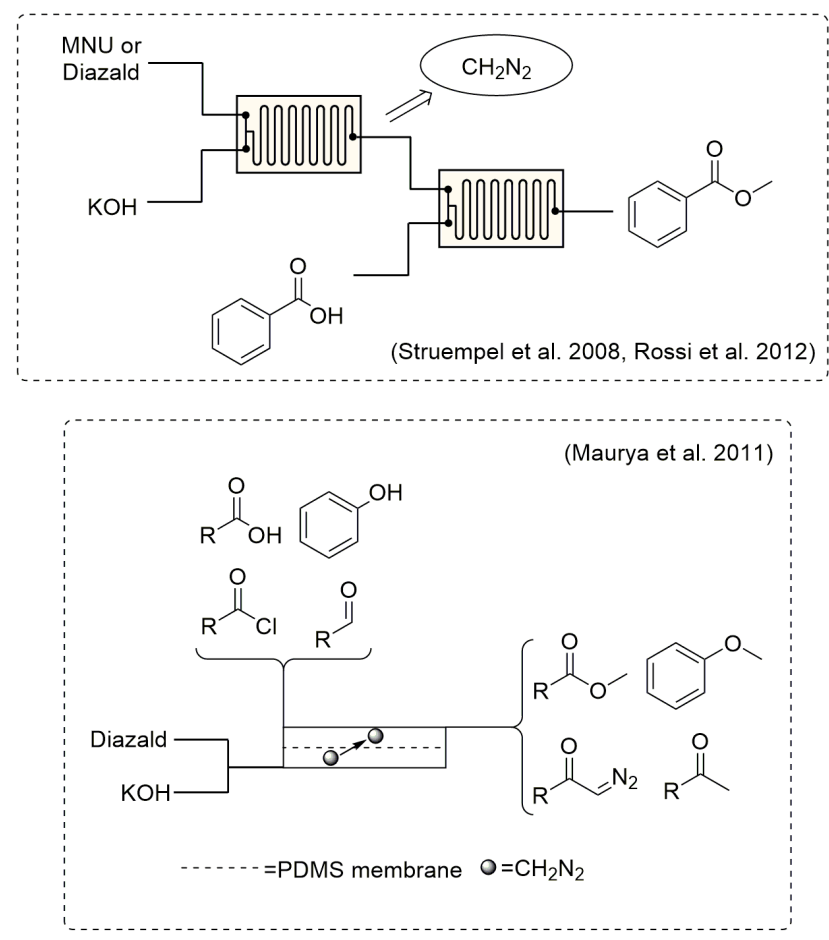

Figure 14 - In situ generation of diazomethane and dual-channel microreactor with membrane for diazomethane extraction.

generation of anhydrous solutions of diazomethane. The diazomethane generated was selectively separated from the Teflon tubing into a substratefilled flask (tube-in-flask reactor). Therefore, the reactor could be employed in several reactions with diazomethane as methylation of carboxylic acids, palladium-catalyzed cyclopropanation, H-X insertion and 1,3-dipolar cycloaddition (Dallinger et al. 2016) (Figure 16).

Ley and co-workers have investigated the production of diazoketones under continuous flow using the safer, but more expensive, (trimethylsilyl)-diazomethane instead of Diazald as the precursor of diazomethane. In the next step, the diazoketones were employed in cycloaddition reactions for the formation of quinoxalines (Martin et al. 2011). Trimethylsilyl diazomethane was also used for homologation reactions with a mixed anhydride derived from $N$-Boc- $(S)$-phenylalanine to synthesize a pharmaceutically relevant intermediate in a continuous flow microreactor (Pollet et al. 2009).

The generation of diazomethane in a continuous process constitutes a safety improvement in the synthesis of diazoketones on a laboratory scale. The use of a continuous flow setup can avoid the distillation and handling of large amounts of diazomethane and, consequently, can reduce the risks of long time exposed and of accidental explosion.

\section{DIAZO TRANSFER REACTION}

The concept of diazo group transfer was first investigated by Dimroth in 1910 (Dimroth 1910). However, the general method for the preparation of diazo compounds employing diazo transfer reactions was established only some years later, after extensive studies by Regitz and collaborators (Regitz 1964, 1967, 1972, Regitz and Heck 1964, Regitz and Maas 1986). This technique allowed the synthesis of cyclic $\alpha$-diazocarbonyl compounds 


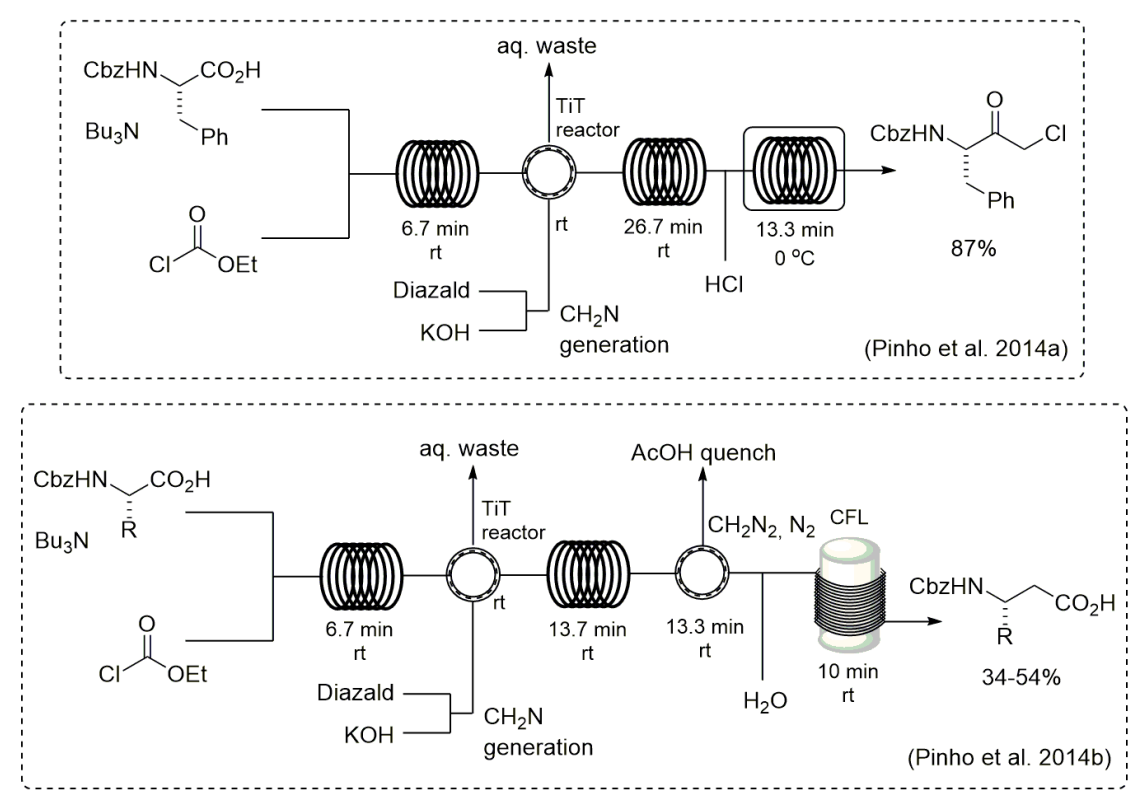

Figure 15 - Generation of diazomethane in a tube-in-tube (TiT) reactor.

as well as many acyclic systems that cannot be accessed by the acylation of diazomethane.

In general, the diazo transfer method involves transferring the diazo group from a donor, such as a sulfonyl azide, to an acceptor which must be a carbonyl compound with relative acidity in the $\alpha$-position. There are two types of acceptors: one that the position of the $\alpha$-carbonyl methylene group is already reactive towards diazo transfer reactions and another that requires prior activation with base to ensure the transfer of the diazo group. Thus, 2-diazo-1,3-dicarbonyl compounds can be formed from malonic esters, $\beta$-ketoesters, $\beta$-ketoamides,

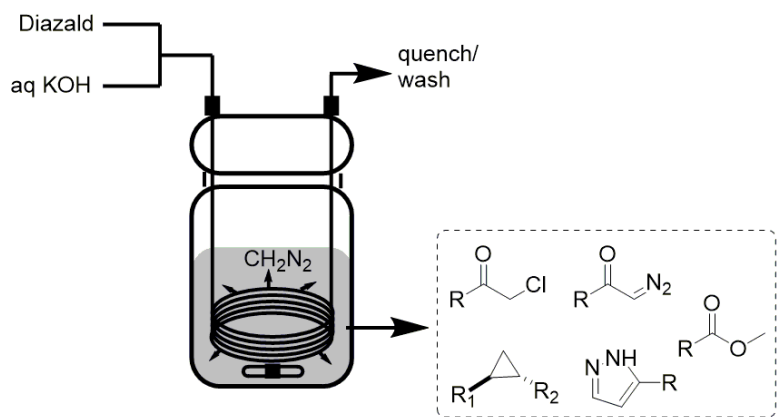

Figure 16 - In situ generation of anhydrous solutions of diazomethane in a semibatch apparatus. and $\beta$-diketones by the diazo transfer procedure using tosyl azide (Santiago 2015) in the presence of triethylamine as the base (Figure 17). The advantage in using this method instead of the acylation of diazoalkanes is the mild reaction conditions and the fact that it does not require the use of diazomethane. Effects of the base and solvent on diazo transfer reactions were also studied by some groups (Doyle et al. 1998). Recently, Sá and co-workers demonstrated the use of molecular sieves (Dutra et al. 2014) and catalytic $t-\mathrm{BuNH}_{2}$ (Costin et al. 2017) for the efficient and mild diazo transfer reactions.

However, the direct diazo transfer reaction generally fails when the methylene group is activated only by a single carbonyl rather than two flanking carbonyl functions. To solve this problem, Regitz and co-workers developed the "deformylating diazo-group-transfer" strategy (Regitz 1967, Regitz and Rüter 1968, Regitz and Menz 1968). First, the substrate is activated by a Claisen condensation of the ketone with ethyl formate in the presence of sodium to provide 1,3-dicarbonyl compounds. Thereafter, the additional activating formyl group 


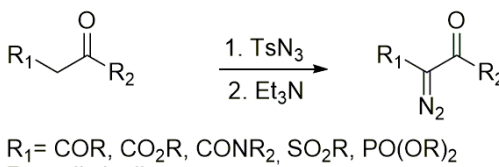
$\mathrm{R}_{2}=$ alkyl, alkoxy<smiles>CCOC(=O)C(=N[13CH][10CH2])C(=O)OCC</smiles><smiles>N=C1C(=O)CNC1=O</smiles><smiles>CCCCC(=O)C(=[W])Oc1ccccc1</smiles>

$88 \%$ (Lowe and Yeung 1973) (Kennedy et al. 1990)

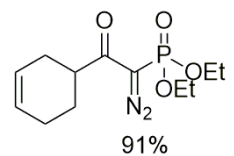

(Callant et al. 1984)

Figure 17 - Preparation of diazocarbonyl compounds by simple diazo transfer reaction.

is removed in the course of the diazo transfer reaction (a deformylation) via a fragmentation reaction from a triazolinic intermediate. Several types of acyclic and cyclic $\alpha$-diazoketones, as well as $\alpha, \beta$-unsaturated diazoketones, could be synthesized by this approach (Regitz et al. 1967, 1970, 1971) (Figure 18). Gupta and co-workers proposed a simple modification in this method to improve the preparation of $\alpha, \beta$-unsaturated diazoketones. Diethyloxalate was used as the activation group instead of the ethyl formate in the Claisen condensation which, after the diazo transfer reaction, afforded unsaturated diazoketones with improved yields (Harmon et al. 1974).

In 1985, Doyle introduced substrate activation employing a trifluoroacetyl group to achieve diazo transfer to a base sensitive $N$-acyloxazolidinone derivative (Doyle et al. 1985). A few years later, Danheiser and co-workers used a similar strategy in which the trifluoroacetyl group was used as an activator to solve some of the limitations of the Regitz and Guta procedure, mainly to synthesize $\alpha, \beta$-unsaturated diazoketones (Danheiser et al. 1990, 1996). The harsh conditions typically required for the Claisen condensation and the low regioselectivity in the formation of the enolates prior to the condensation step could be avoided with Danheiser's method. Thus, the modification in the Regitz deformylating procedure consisted of the generation of methyl ketone enolates from kinetic conditions (LiHMDS, $-78{ }^{\circ} \mathrm{C}, 30 \mathrm{~min}$ ) and the use of the very reactive acetylation agent, trifluoroethyl trifluoroacetate (Figure 19).

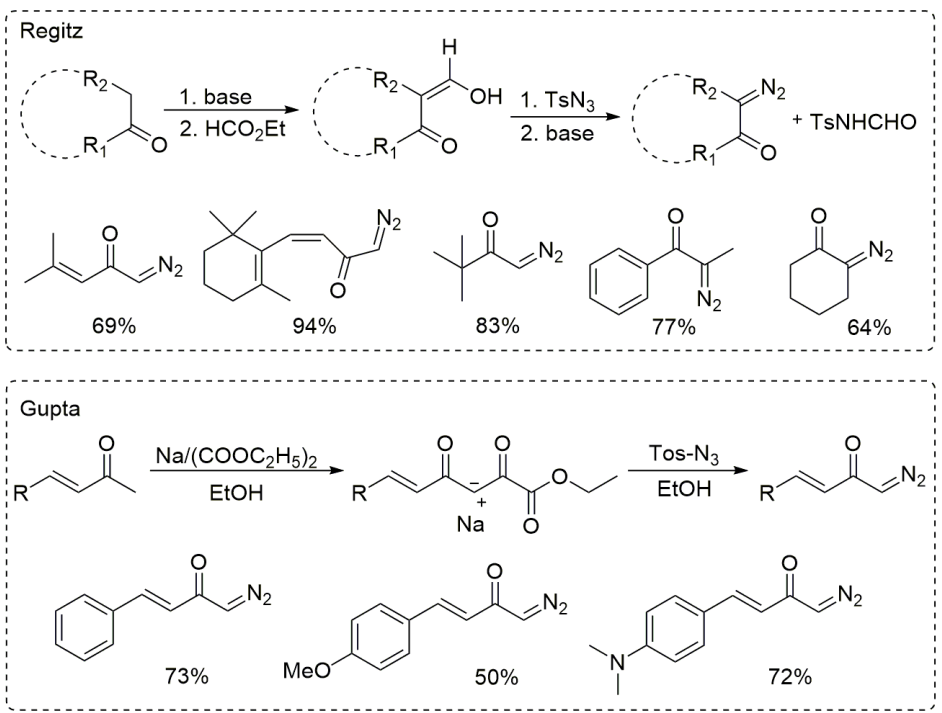

Figure 18 - Regitz and Gupta deformylating diazo transfer procedure for the preparation of diazoketones. 


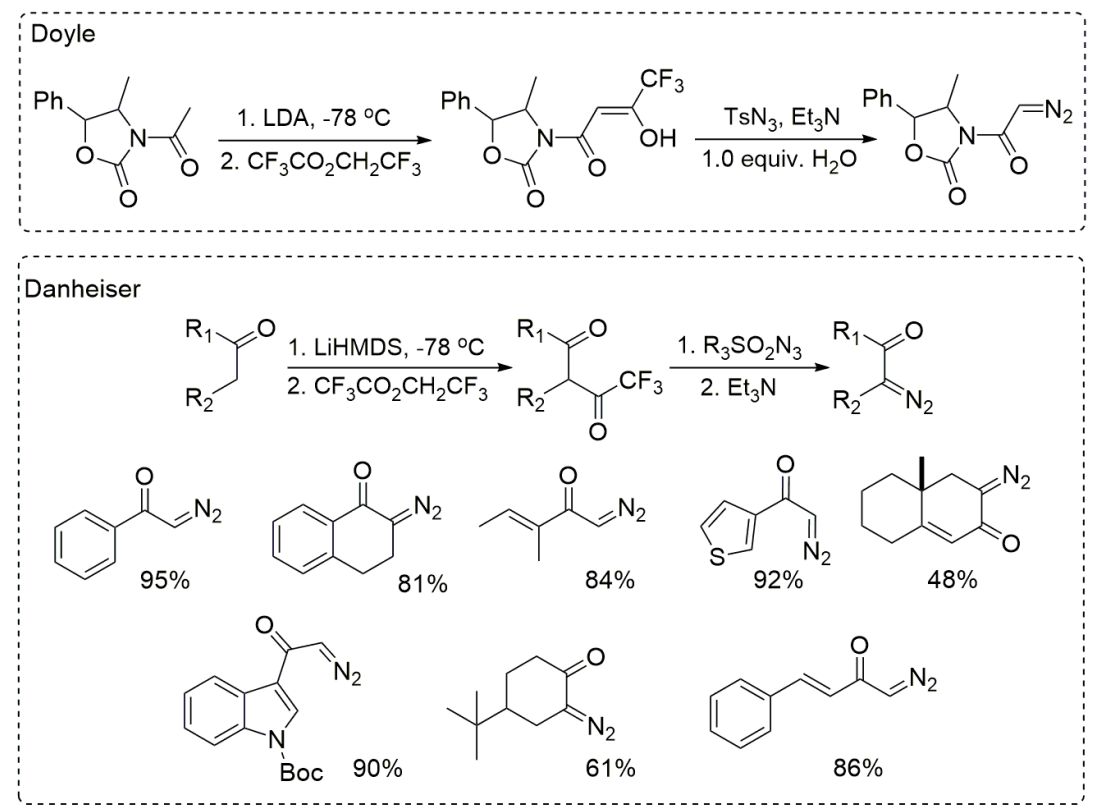

Figure 19 - Trifluoracetylation/detrifluoroacetylation diazo transfer method.

Another modification of the Regitz's procedure that was useful in the synthesis of diazoesters and ketones involved an initial activation by benzoylation. Taber and co-workers established a method that allowed the construction of unsymmetrical $\alpha$-diazoketone employing benzoylacetone as the starting material. In this technique, benzoylacetone could be alkylated in different positions ( $\alpha$ - or $\alpha$ - and $\gamma$-position) to provide unsymmetrical ketones followed by debenzoylation and diazo transfer in the presence of $p$-nitrobenzenesulfonyl azide (p-NBSA) and 1,8-diazobicyclo[5.4.0] undec-7-ene (DBU) (Taber et al. 1995). Ten years later, Taber and co-workers modified their benzoylation/debenzoylation diazo transfer process by a titanium chloride-mediated benzoylation for activation of the ester, followed by diazo group transfer under mild conditions (Taber et al. 2005) (Figure 20).

An effective method for diazocarbonyl transfer was described by Badet and co-workers in which succinimidyl diazoacetate was employed in direct diazoacetylation of amines, phenols, thiophenol, and peptides under mild conditions (Ouihia et al.
1993). Three years later, Doyle and co-workers developed an improved method for synthesis of succinimidyl diazoacetate which furnished diazoacetamides in good yields (Doyle and Kalinin 1996) (Figure 21).

Recently, Wang, $\mathrm{Hu}$ and collaborators have published a highly efficient synthesis of $\alpha$-diazoketones by a tandem reaction with a novel primary amine-catalyzed Regitz diazo-transfer of 1,3-diketones and a novel primary amine-mediated $\mathrm{C}$-C bond cleavage of 2-diazo-1,3-diketones. Several $\alpha$-diazoketones could be prepared in good yields by stirring 1,3-diketones together with tosyl azide and methylamine in ethanol (Zhang et al. 2017) (Figure 22).

Although diazo transfer is a safe alternative procedure for synthesizing diazocarbonyl compounds, the thermal stability of the transfer agent and the difficult of removing the sulfonamide by-product are some limitations of the Regitz's method. In view of this, the search for better alternatives to tosyl azide and to other diazo transfer reagents were necessary. Although this search continues, various sulfonyl azide derivatives 


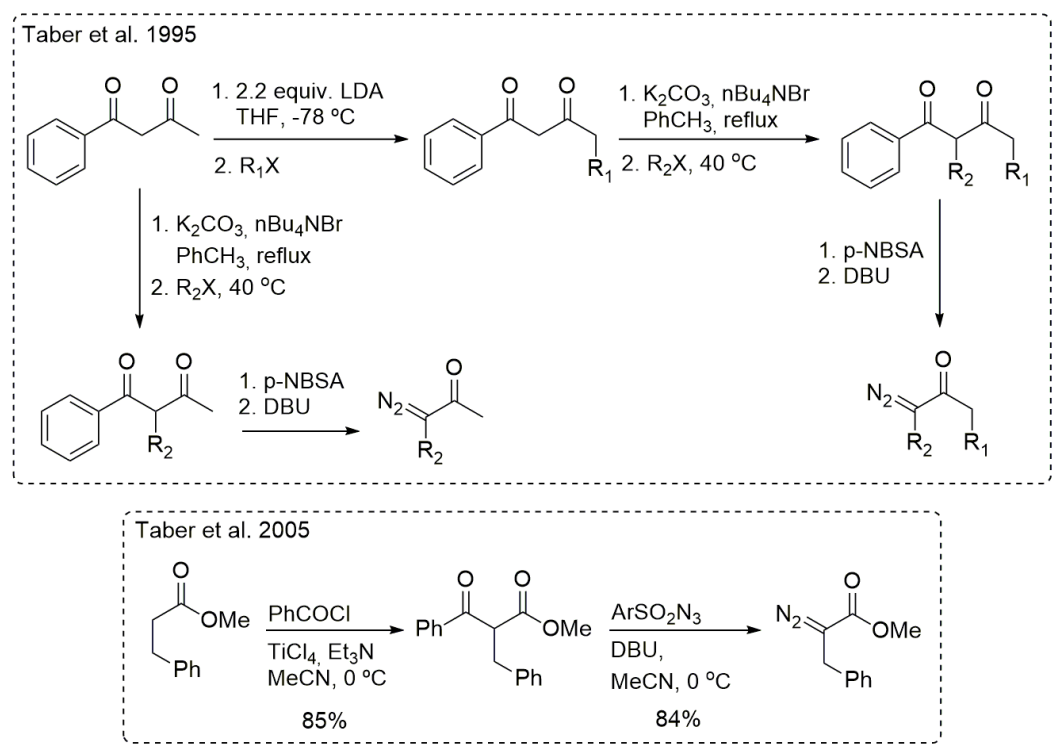

Figure 20 - Benzoylation/debenzoylation diazo transfer procedure described by Taber and co-workers.

could already be described as substitutes for $p$-tosyl azide in the diazo transfer reactions (Figure 23).

In addition to the list of diazo transfer reagents, a stable and accessible imidazolesulfonyl azide hydrochloride has been reported by GoddardBorger and Stick. It could easily be prepared in a one-pot reaction on a large scale from sodium azide, sulfuryl chloride, and imidazole (GoddardBorger and Stick 2007). Klapötke and co-workers improved the stability of this reagent with respect to shock sensitivity by replacing the counterion in imidazolesulfonyl azide with tetrafluoroborate or hydrogen sulfate (Fischer et al. 2012) (Figure 24). Although imidazolesulfonyl azide hydrochloride is reported as a stable compound, there is still concerns about its preparation. By-products that can be formed in the preparation of this transfer agent can react with reaction intermediates and provide highly explosive species such as hydrazoic acid and sulfuryl diazide (Ye et al. 2013). One solution to this was proposed by Wang and co-workers who developed a two-step alternative procedure using sulfuryl diimidazole as a starting material under non-acidic conditions. In addition, the free base imidazolesulfonyl azide could be prepared in situ and could be used directly as a transfer agent (Ye et al. 2013) (Figure 24).

Other diazo transfer reagents have been recently described in the literature. For example, Katritzky and co-workers developed a stable and crystalline benzotriazole-1-sulfonyl azide. However, its preparation involved the use of sulfuryl dichloride and sodium azide which may form explosive by-products (Katritzky et al. 2010, Katritzky and El Khatib 2012). On the other hand, Chiara and Suárez reported the synthesis of a shelfstable nonafluorobutanesulfonyl azide that does not require the dangerous mixture of sulfuryl dichloride and sodium azide (Chiara and Suárez 2011). In addition, Kitamura and co-workers developed 2-azido-1,3-dimethylimidazolinium salts as a novel class of diazo transfer reagents which exhibited negative impact in sensitivity tests as well as high decomposition temperatures $\left(200{ }^{\circ} \mathrm{C}\right)$. Therefore, the imidazolinium salts were more stable than other reported transfer reagent and the by-product of the reaction was a highly water-soluble imidazolinones (Kitamura et al. 2011, 2014). 


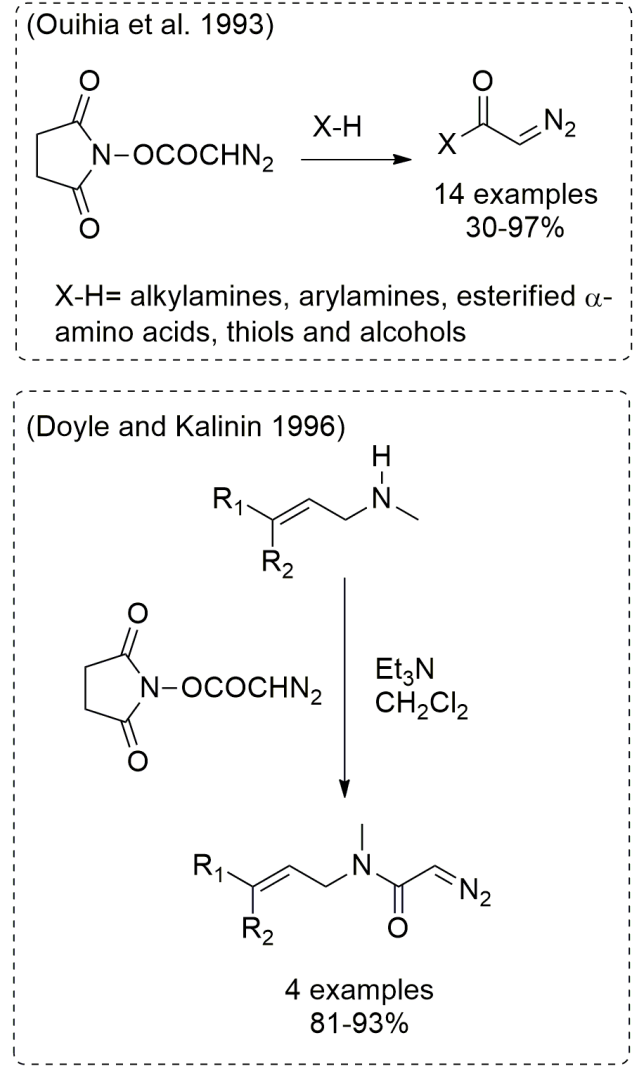

Figure 21 - Diazocarbonyl transfer method.

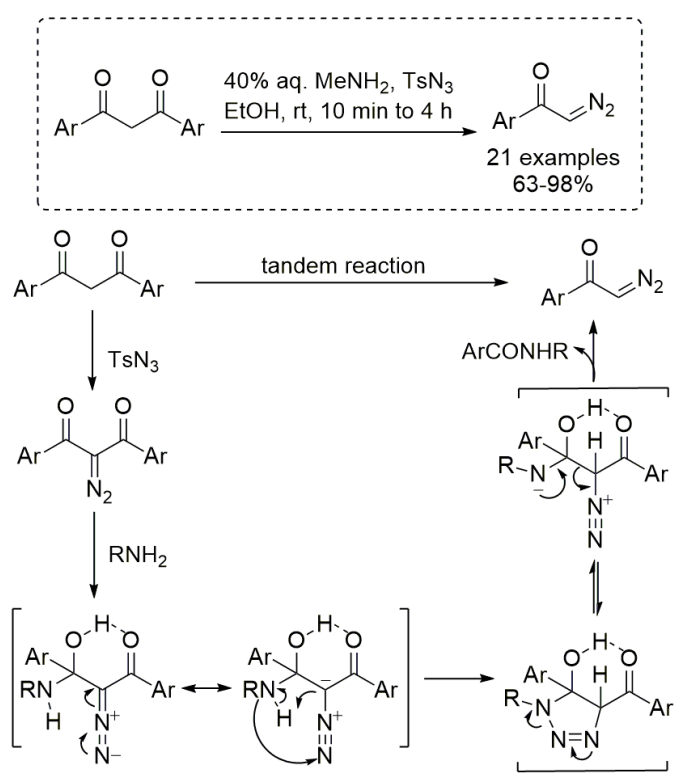

Figure 22 - A tandem reaction synthesis of $\alpha$-diazoketone.

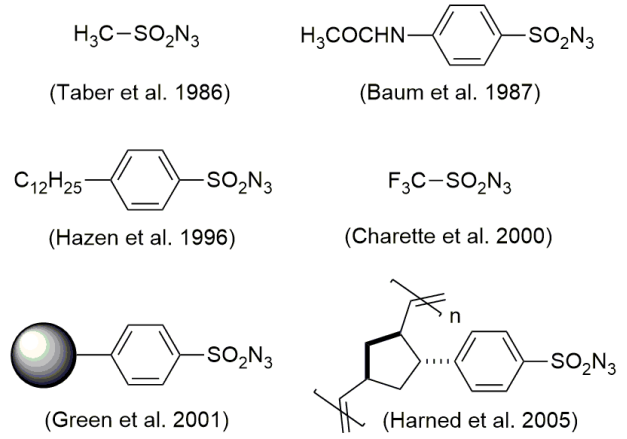

Figure 23 - Sulfonyl azide derivatives that have been used as an alternative to tosyl azide.

The improvements in the diazo transfer approach were not only in the search for new reagents, but also in the exploration of new developments and adaptations of the Regiz's methodology. In this regard, Ramachary and collaborators have studied diazo transfer reactions in ionic liquids, such as 1-butyl-3-methylimidazolium (bmim) salts. Thus, various 2-diazo-1,3-dicarbonyl compounds could be synthetized from acyclic and cyclic 1,3-diketone and $\beta$-ketoester derivatives, employing $p$-tosyl or mesyl azide and catalytic amounts of 4-dimethylaminopyridine (DMAP) (Ramachary et al. 2008). Another new method was reported by Kumar and co-workers who first synthetized an ionic liquid-supported sulfonyl azide as diazo transfer reagent. They applied this new reagent on diazo transfer as well as on the detrifluoroacetylative diazotransfer reactions under solvent free conditions. This method offered a better way to purify the products and, consequently, numerous diazocompounds could be isolated in excellent yields and in high purity (Muthyala et al. 2012) (Figure 25).

Collins and co-workers developed a green and environmentally friendly method for diazo transfer reactions with a variety of $\beta$-ketoesters precursors using a safer polymer-supported benzenesulfonyl azide and a catalytic amount of base in water. With this methodology, the $\alpha$-diazo- $\beta$-ketoesters could be obtained after a simplified work up (filtration of 


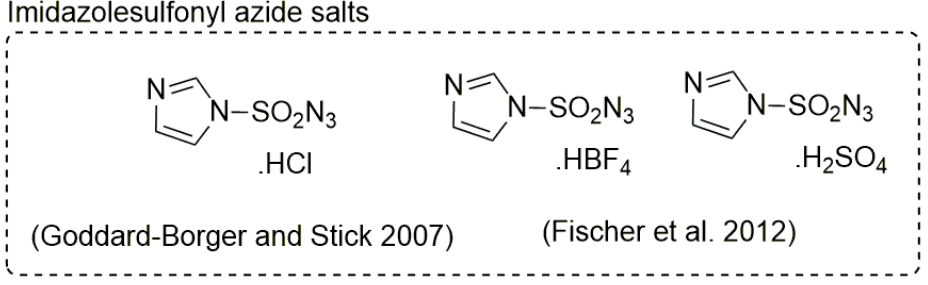

Two-step synthesis of imidazolesulfonyl azide:

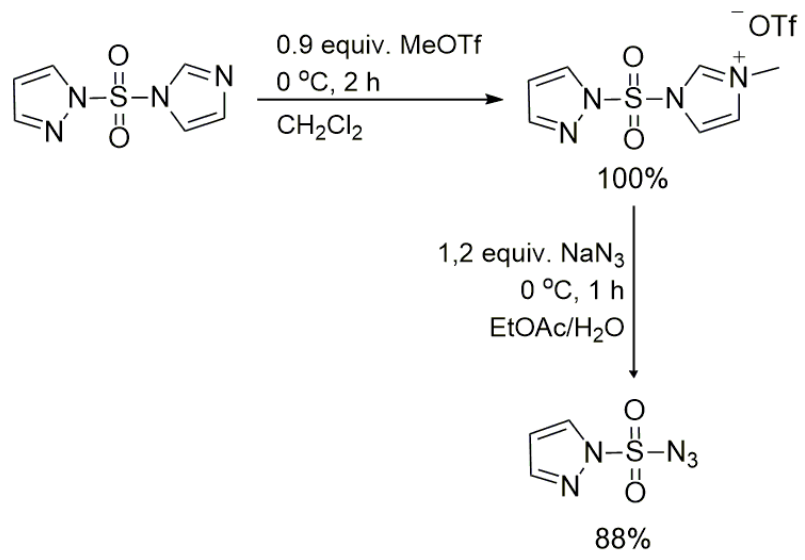

Figure 24 - Imidazolesulfonyl azides salts and two-step synthesis of free base imidazolesulfonyl azide.

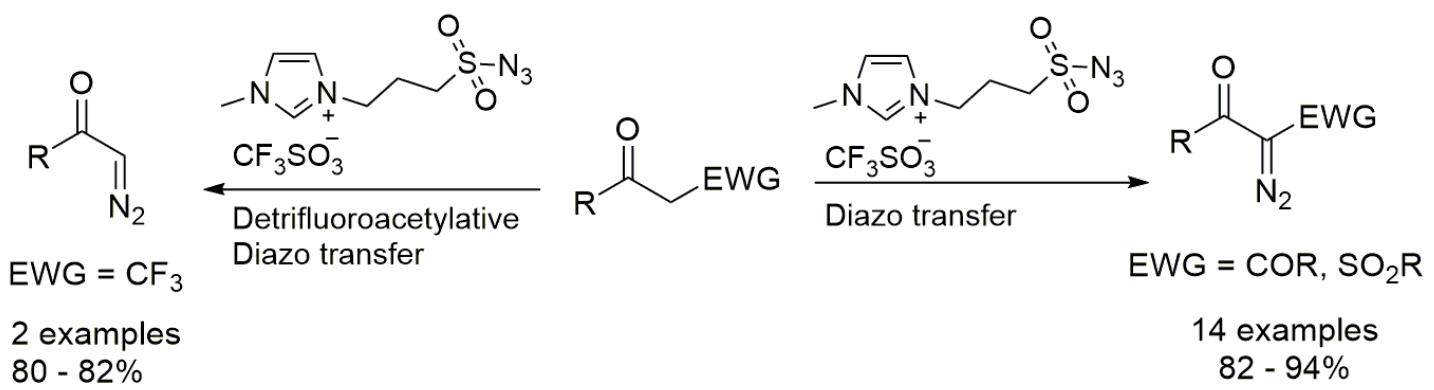

Figure 25 - Application of ionic liquid-supported sulfonyl azide in diazotransfer reaction.

a resin bound sulfonamide by-product) (Tarrant et al. 2016) (Figure 26).

Another improvement in the separation of the sulfonamide by-product was the development of a magnetic benzenesulfonyl azide as a transfer agent in diazo transfer reactions by Hanson and collaborators (Faisal et al. 2017). The magnetic sulfonamide by-product was separated by simple magnetic decantation and the reaction mixture was treated sequentially with $\mathrm{Rh}_{2}(\mathrm{OAc})_{4}$ by using a one pot procedure affording a 1:1 mixture of dihydrofuran and $\alpha$-haloenones in $90 \%$ overall yield (Figure 27).

Finally, Collins, Maguire and co-workers have explored the diazo transfer reactions in a continuous process. In their work, tosyl azide was generated in situ and used sequentially in diazo transfer reactions with various type of acceptors such as $\beta$-ketoesters, $\beta$-ketoamides, malonate esters and $\beta$-ketosulfones. The development of an effective in-line quench of sulfonyl azides employing a sacrificial acceptor molecule ensured complete removal of the 


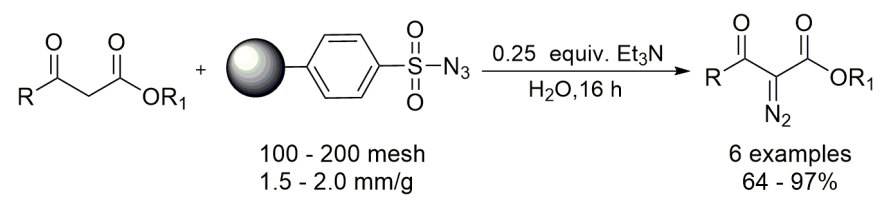

Figure 26 - A green diazo transfer method using polymer-supported benzenesulfonyl azide and catalytic amount of base in water.

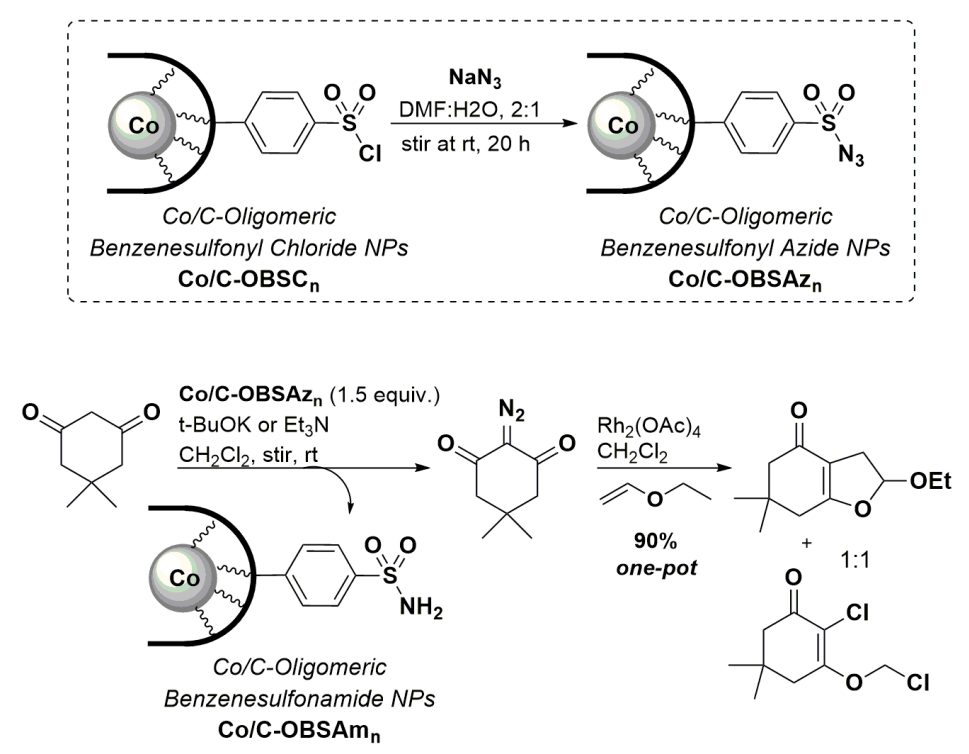

Figure 27 - Magnetic benzenesulfonyl azide as transfer agent in diazo transfer reactions.

unreacted tosyl azide. Thus, the application of the continuous process allowed to work with a large scale diazo transfer reaction in which more than 21 $\mathrm{g}$ of a $\alpha$-diazocarbonyl could be obtained in high purity (>98\%) without column chromatography. Moreover, the used of the continuous process in these reactions minimized the risks associated with handling hazardous and explosive reagents on large scale (Deadman et al. 2016). This group also studied the continuous-flow generation of $\alpha$-diazosulfoxides using a bed of polystyrenesupported base (PS-DBU or PS-NMe2), a safe diazo transfer reagent dodecylbenzenesulfonyl azide (DBSA) and a high control of the residence times (McCaw et al. 2016). With the results of these studies, they could synthesize several novel $\alpha$-diazo- $\beta$-keto sulfoxides at higher yields and at shorter reaction times than batch conditions (McCaw et al. 2017) (Figure 28).
The continuous flow technique was also employed by Wirth and co-workers in their studies on diazo transfer and diazo decomposition reactions. In-line IR analyses in flow allowed quick access to quantitative information on diazo formation and consumption. After the optimizations of the reactions, they established a multistep process in continuous flow involving diazo group transfer, extraction, separation and subsequent diazo decomposition with several X-H insertion reactions (Müller et al. 2015). Later, they applied their methodology in the synthesis of a key intermediate in the pathway for milnacipran analogs (Müller et al. 2016) (Figure 29).

\section{DIAZOTIZATION OF AMINES}

Diazotization of amines can be performed by the reaction between a primary amine and a nitrosating agent, such as sodium nitrite $\left(\mathrm{NaNO}_{2}\right)$, in the 


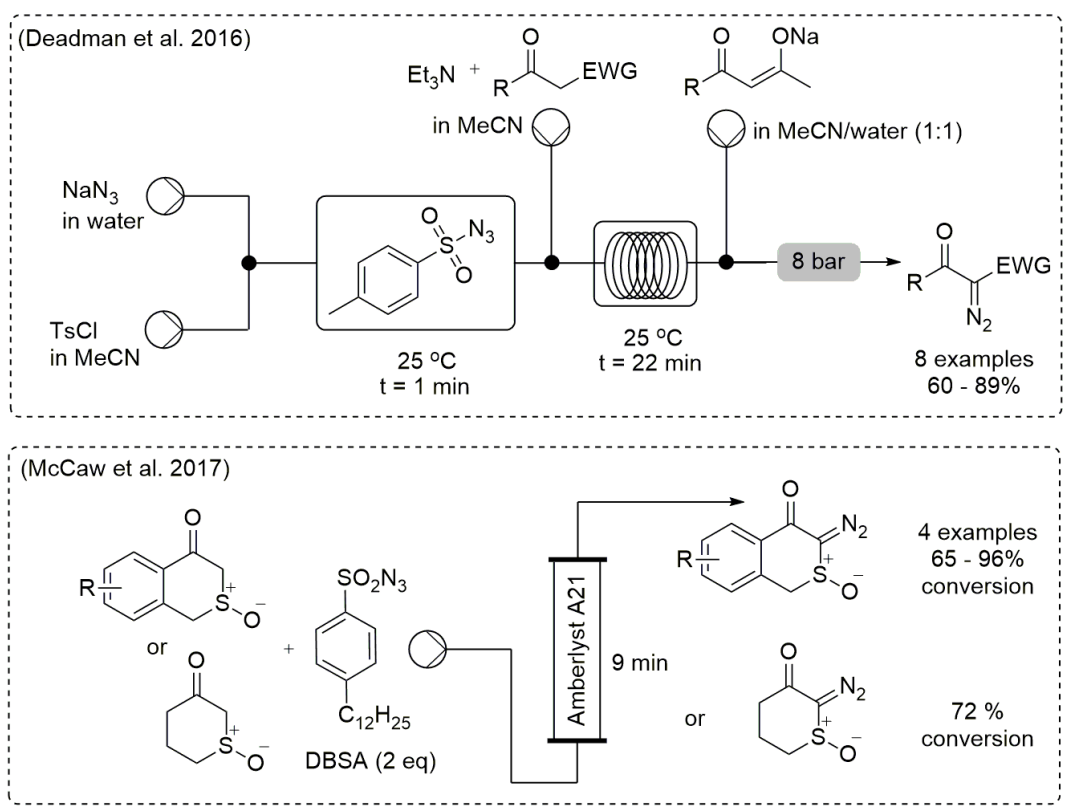

Figure 28 - Large scale synthesis of $\alpha$-diazocarbonyl compound and synthesis of $\alpha$-diazo- $\beta$-keto sulfoxides under continuous flow conditions.

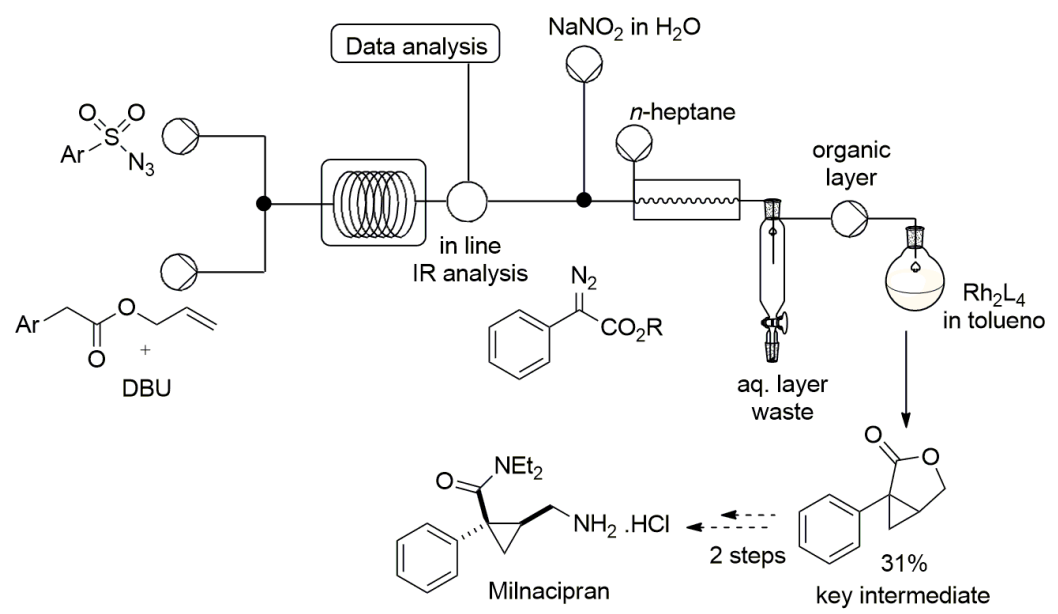

Figure 29 - Prepare of a key intermediate in the synthesis of milnacipran by diazo transfer reaction in continuous flow.

presence of an acidic aqueous solution. (Doyle et al. 1998) (Figure 30).

Over the years, a methodology based on a primary amine and a nitrosating agent to perform diazo syntheses has been expanded to fluorinated diazoalkanes and monofluorosubstituted diazoalkanes (Mykhailiuk 2014, 2015, 2017). For example, a novel chemical reagent, heptafluoroisopropyl diazomethane $\left(\mathrm{i}-\mathrm{C}_{3} \mathrm{~F}_{7} \mathrm{CHN}_{2}\right.$ ), which has been generated in situ, can react with electron-deficient alkyl groups and polyfluoro pyrazoles (Mykhailiuk 2017) (Figure 31). Another example is the generation of 2-diazo-1,1,1trifluoroethane $\left(\mathrm{CF}_{3} \mathrm{CHN}_{2}\right)$ which can work as a carbene donor for the asymmetric synthesis of trifluoromethyl substituted cyclopropanes (Tinoco et al. 2017) (Figure 31). 


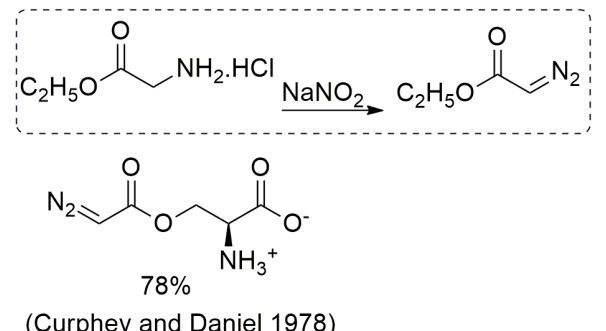

Curphey and Daniel 1978)
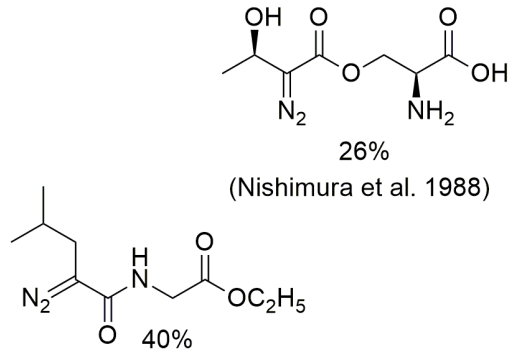

(Challis and Latif 1990)

Figure 30 - Some applications of the amine diazotization method to produce ethyl diazoacetate.

DEHYDROGENATION OF HYDROZONES, TOSYLHYDRAZONES AND OXIMES

Dehydrogenation of hydrazones is one of the oldest methods for the synthesis of diazo compounds (Doyle et al. 1998). It comprises of an oxidation reaction of hydrazine with numerous metallic catalysts as oxidizing agents, consisting mainly of heavy metals such as mercury oxide, silver oxide, manganese dioxide, lead (IV), among others (Holton and Shecter 1995) (Figure 32).

Alternative routes have been developed to reverse the use of heavy metals in the dehydrogenation reaction of hydrazones. A novel metal free pathway capable of generating various substituted diazomethane derivatives is based on chlorosulfodimethyl chloride, also known as Swern's reagent, which can be produced in situ by the reaction between DMSO and oxalyl chloride in the presence of triethylamine as base (Javed and Brewer 2007) (Figure 33).

Another metal free alternative for the formation of diazo compounds is provided by the oxidation of $\mathrm{N}$-(tert-butyldimethylsilyl)hydrazones employing (difluoroiodo) benzene. In this reaction, the

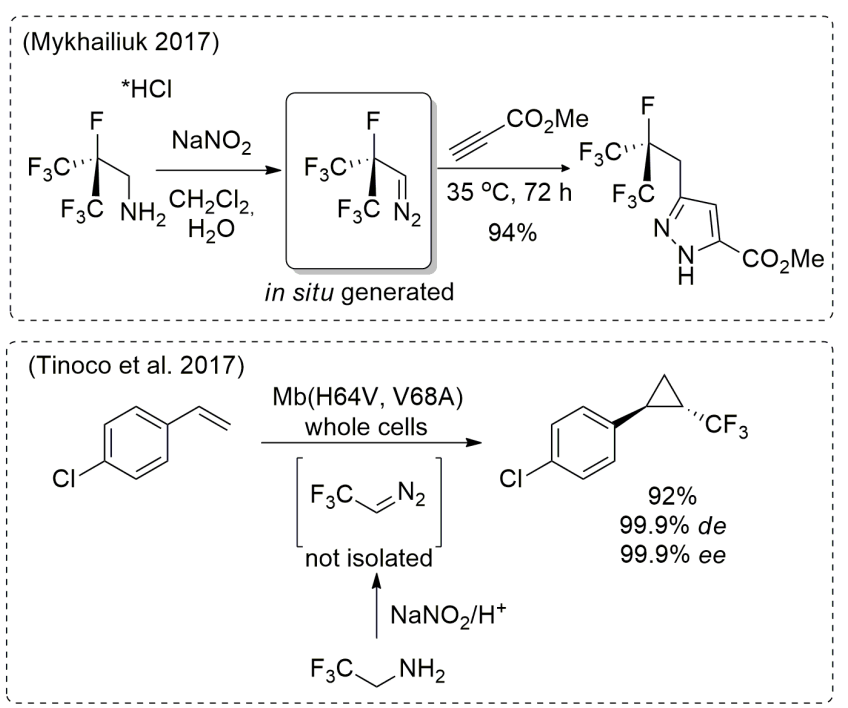

Figure 31 - Examples of synthesis and applicability of fluorinated diazoalkanes.

diazotized product can be immediately consumed in the presence of a carboxylic acid during the oxidation step, yielding carboxylic esters (Furrow and Myers 2004) (Figure 34).

In addition to the dehydrogenation of hydrazones, there is another methodology developed by Aller and co-workers which is a very useful and efficient strategy for the synthesis of $\alpha$-diazoketones using $N$-isocyanotriphenylimino phosphorene as a substitute for diazomethane. This methodology was based on the formation of a diazoketone through the conversion of a hydrazidoyl intermediate and aims to decrease the known limitations of the direct acylation of diazomethane (Aller et al. 2000) (Figure 35).

A widely used method for obtaining diazo compounds from hydrazones is the cleavage of toluenesulfonyl hydrazones, also known as the Bamford-Stevens reaction (Bamford and Stevens 1952). This reaction consists in the base cleavage of the tosylhydrazones (which are usually synthesized from tosylhydrazides and aldehydes or ketones) to provide the corresponding diazocarbonyl 


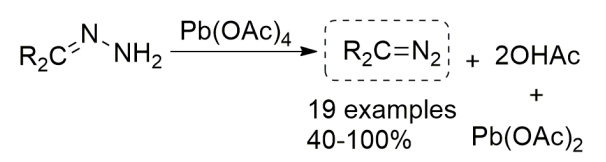

Figure 32 - General dehydrogenation reaction of hydrazones.

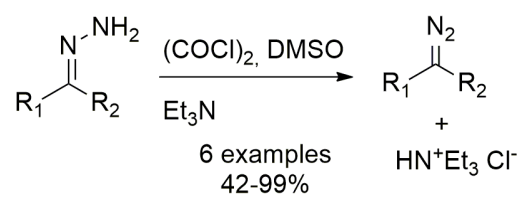

Figure 33- New route for dehydrogenation of hydrazones.

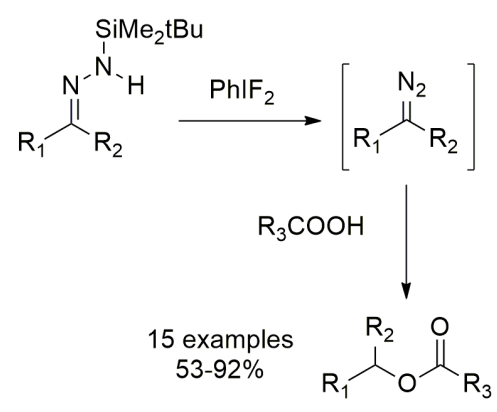

Figure 34- Alternative route for dehydrogenation of hydrazones.

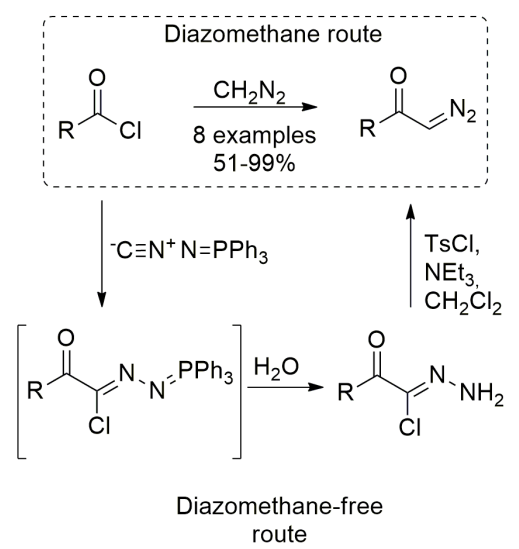

Figure 35- Diazomethane-free conversion of acyl chlorides to diazoketones.

compounds as depicted in Figure 36 (Doyle et al. 1998).

Over the years, adaptations and modifications have been made in the Bamford-Stevens synthesis. One of them, performed by House, consisted in the preparation of $\alpha$-diazoesters that were difficult to access by the original method (House and Blanke 1968). The modified reaction was based on the conversion of glyoxylic acid to its corresponding tosylhydrazone, followed by reaction with thionyl chloride. Reaction of the acid chloride reagent with an alcohol gives the hydrazone ester, that is subsequently decomposed by two equivalents of triethylamine to give the diazoester (Figure 37).

Although the House's method showed satisfactory results for the synthesis of $\alpha$-diazoesters, products were not always obtained in the pure form (sulfonate contamination). Considering this fact, Corey and Myers proposed other modifications to provide better control in the formation of by products (Corey and Myers 1984). This modification was based on the replacement of one equivalent of triethylamine by one of a weaker base, for example, $N, N$-dimethylaniline (Figure $38)$.

House's method is efficient in converting alcohols to diazoacetates, but obtaining the products takes three steps, due to the preparation of the acid chloride reagent from glyoxylic acid. Fukuyama and co-workers developed a new methodology to convert alcohols into the corresponding diazoacetates in a shorter number of steps. The method employs readily manipulatable and accessible reagents. For example, bromoacetates of the corresponding alcohols are treated with $N, N$ '-ditosylhydrazine and DBU to furnish diazo carbonyl derivatives in good yields (Toma et al. 2007) (Figure 39).

The reaction from oximes, also known as the Forster reaction, was first reported in 1915 (Forster 1915). This reaction consists in the synthesis of diazoketones, especially the cyclic ones, from the reaction of $\alpha$-ketoximes with chloramines. Forster's reaction has wide applicability in the preparation of $\alpha$-diazoketones and derivatives (Figure 40). 


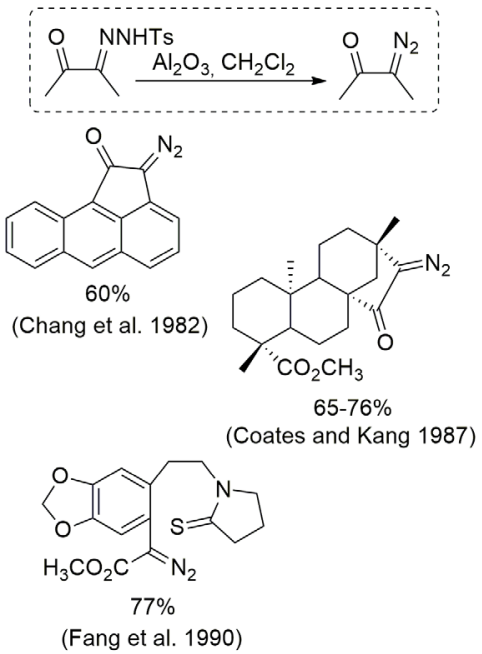

Figure 36 - Examples of Bamford-Stevens reactions to convert carbonyl compounds in diazo derivatives.

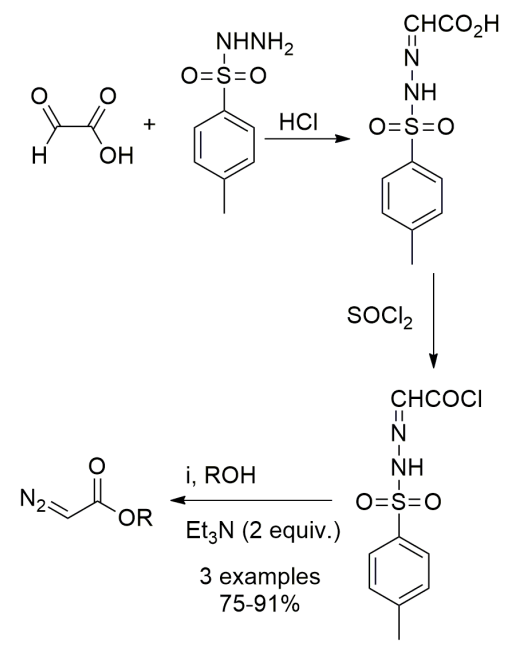

Figure 37 - Reaction described by House for the synthesis of $\alpha$-diazoesters.

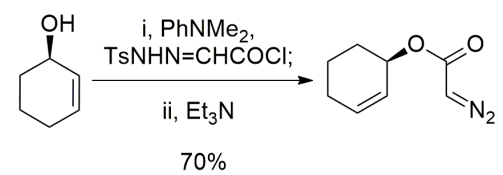

Figure 38 - Example of the House method modification proposed by Corey and Myers.

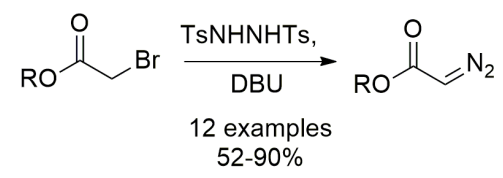

Figure 39 - Synthesis of diazo compounds from bromoacetates.

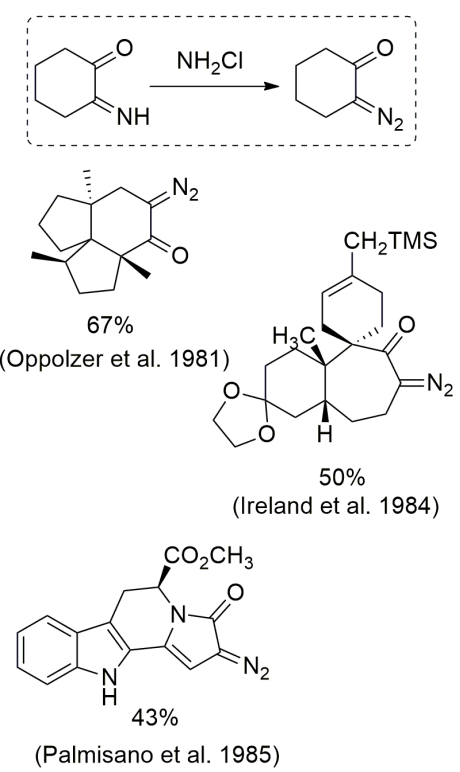

Figure 40 - The Forster's reaction.

\section{TRIAZENE FRAGMENTATION}

Triazenes are produced by the coupling of diazonium salts with primary amines. They act as precursors of diazo compounds since their fragmentation with an acid or a base generates an $\alpha$-diazocarbonyl and an aromatic amine (Baumgart 1967, Schroen and Brase 2005) (Figures 41 and 42).

Although such methodology is efficient for the preparation of diazo compounds, it provides low to moderate yields, which makes the method limited. Considering this fact, Myers and Raines have developed a novel approach for preparing these compounds, maintaining the fragmentation of an acyltriazene as the key step. This method consisted of the reaction between a phosphine and an azide to form an phosphazide compound, which undergoes a fragmentation to afford a carboxamide and a $\alpha$-diazoacetamide (Myers and Raines 2009) (Figure 43). This reaction can be extended to other diazo compounds, depending on the azide employed.

To increase the applicability of the reaction described by Myers and Raines and to insert it into the biological environment, Chou and Raines 


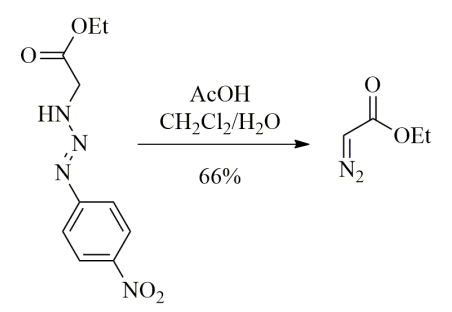

Figure 41 - Acid catalyzed fragmentation of an aryl triazene derivative for the formation of ethyl diazoacetate.

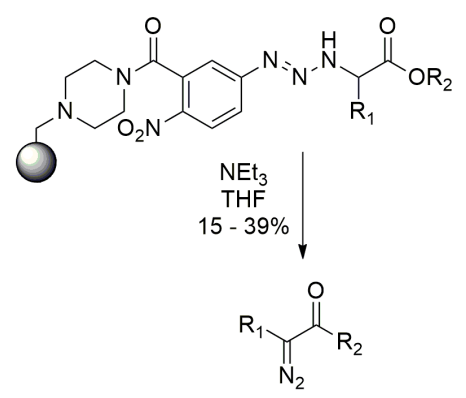

Figure 42 - Fragmentation of a triazene derivative under basic conditions.

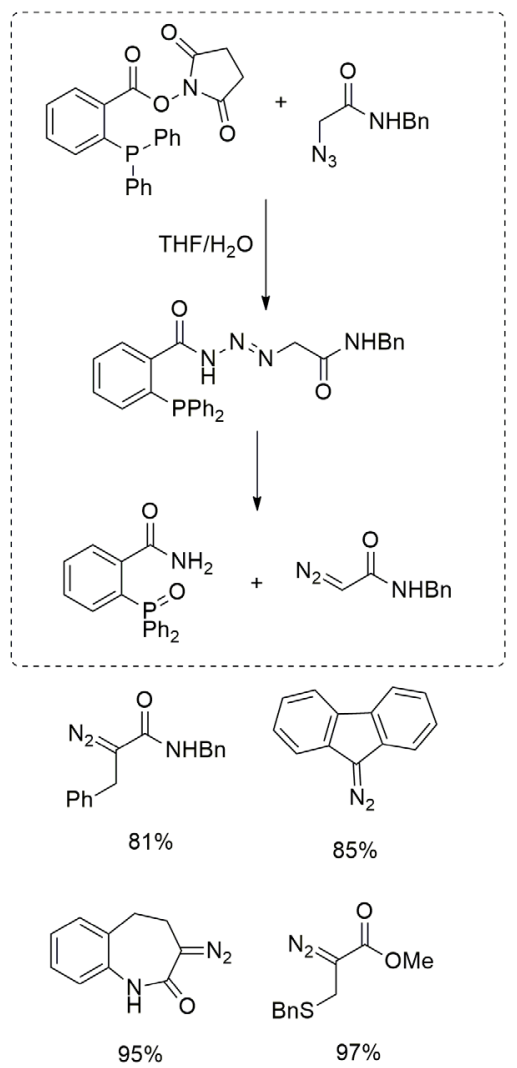

Figure 43 - Conversion reaction of organoazides to diazo compounds mediated by phosphine. recently developed a new phosphine compound. This phosphine can mediate the conversion of the azide to diazo compounds under the conditions of phosphate buffer at neutral $\mathrm{pH}$ and ambient temperature, like the physiological conditions (Chou and Raines 2013). The diazo compounds prepared from this reagent were obtained in good yields and with a better substrate scope when compared to the previous method (Figure 44).

\section{CHEMICAL MODIFICATION OF DIAZOCARBONYL COMPOUNDS}

\section{SUBSTITUTION AND CROSS-COUPLING AT THE DIAZOMETHYL CARBON}

Another manner to prepare diazocarbonyl derivatives is through the chemical modification of these compounds with the retention of the diazo function. In general, the hydrogen atom of the diazomethyl carbon on terminal and acyclic substrates can be replaced by electrophilic reagents. Fink and Regitz reviewed halogenation, metalation, nitration, and alkylation reactions in which novel substituted diazocarbonyl compounds were obtained (Fink and Regitz 1985). Some examples of substitution reactions on diazomethyl carbon are summarized in Table I.

As revised by Fink and Regitz, the electrophilic halogenation of the terminal diazocarbonyl to produce $\alpha$-halodiazo compounds usually occurs through mercury or silver intermediates. However, Bonge-Hansen and co-workers reported a metalfree procedure for preparing halodiazoacetates through the reaction between diazocarbonyl and $N$-halosuccinimide in the presence of DBU (Kaupang and Bonge-Hansen 2013, Schnaars et al. 2013) (Figure 45).

The substitution reaction at azomethine hydrogen was used by Gosselin and co-workers as a strategy to perform two sequential aldolisations. Initially, the $\alpha$-hydrogen of the diazoketone was substituted by a silyl group to prevent aldolization at 


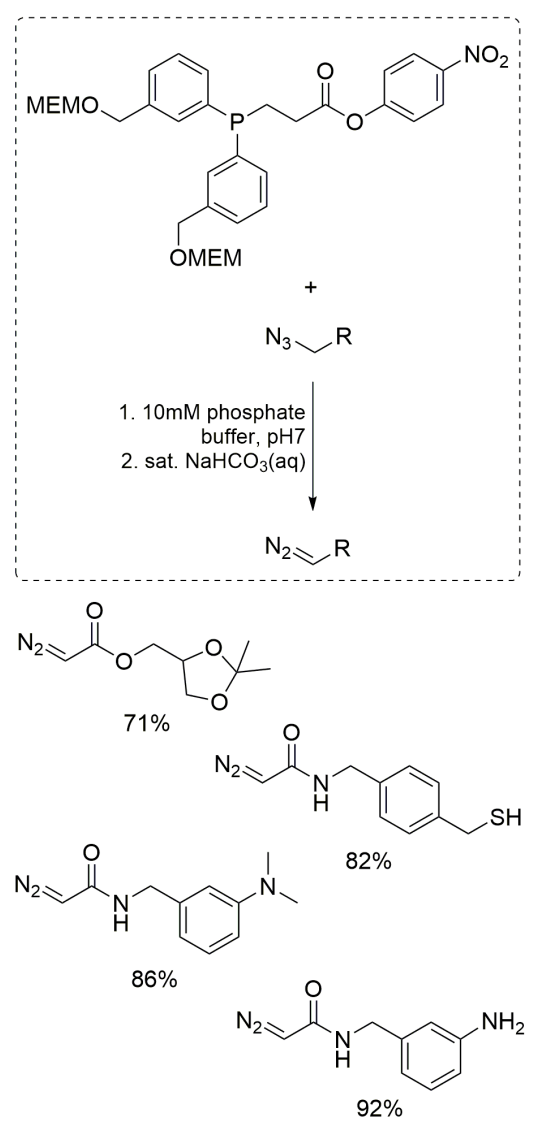

Figure 44 - Development of diazo compounds in water mediated by the developed phosphine. the diazo-side position. Thus, the first aldolization occurred at the methyl-side and the second at the diazo-side position, after desilylation. With this method, 2-diazo-3-oxo-1,5-dihydroxy compounds could be obtained after a second aldolization without the need of O-protection after the first aldol reaction (Lancou et al. 2012) (Figure 46).

Later, the same research group reported the use of $\alpha$-triethylsilyl- $\alpha$-diazoacetone (TESdiazoacetone) in the TBAF-induced aldol-type addition, employing various aldehydes, to yield a broad range of $\beta$-hydroxy- $\alpha$-diazoacetone scaffolds (Abid et al. 2015). Next, $\alpha$-Triisopropylsilyl- $\alpha$ diazoacetones (TIPS-diazoacetone) have been reported as a substitute for TES-diazoacetones. The use of TIPS groups made these compounds more stable than the TES-derivatives (Abid et al. 2017) (Figure 47).

As mentioned above, terminal diazocarbonyl compounds can undergo Aldol-type additions at the diazomethyl carbon. Generally, these reactions are carried out at low temperatures with strong bases, such as lithium diisopropylamide

TABLE I

Substitution reaction of terminal diazocarbonyl compounds.

\begin{tabular}{|c|c|c|c|c|c|}
\hline Reaction & Substrate & Conditions & Product & Yield (\%) & Ref \\
\hline Metallation & $\mathrm{N}_{2} \mathrm{CHCO}_{2} \mathrm{Et}$ & $\begin{array}{l}\mathrm{Ag}_{2} \mathrm{O} \\
\leq 0{ }^{\circ} \mathrm{C}\end{array}$ & $\mathrm{AgCN}_{2} \mathrm{CO}_{2} \mathrm{Et}$ & ---- & $\begin{array}{l}\text { Schöllkopf and } \\
\text { Rieber } 1969\end{array}$ \\
\hline \multirow{5}{*}{ Halogenation } & $\mathrm{N}_{2} \mathrm{CHCO}_{2} \mathrm{Et}$ & $\begin{array}{l}\text { n-BuLi, } \\
-100^{\circ} \mathrm{C}\end{array}$ & $\mathrm{LiCN}_{2} \mathrm{CO}_{2} \mathrm{Et}$ & ---- & Schöllkopf et al. 1974 \\
\hline & $\mathrm{PhCOCHN}_{2}$ & $\begin{array}{l}\mathrm{HgO}, \\
20{ }^{\circ} \mathrm{C}\end{array}$ & $\mathrm{Hg}\left(\mathrm{CN}_{2} \mathrm{COPh}\right)_{2}$ & 97 & Yates et al. 1975 \\
\hline & $\mathrm{Hg}\left(\mathrm{CN}_{2} \mathrm{CO}_{2} \mathrm{Et}\right)_{2}$ & $\begin{array}{l}\mathrm{SO}_{2} \mathrm{Cl}_{2} \\
-30^{\circ} \mathrm{C}\end{array}$ & $\mathrm{ClCN}_{2} \mathrm{CO}_{2} \mathrm{Et}$ & 30 & Schöllkopf et al. 1968 \\
\hline & $\mathrm{Hg}\left(\mathrm{CN}_{2} \mathrm{CO}_{2} \mathrm{Et}\right)_{2}$ & $\begin{array}{l}\mathrm{Br}_{2} \text {, ether-THF } \\
-100{ }^{\circ} \mathrm{C}\end{array}$ & $\mathrm{BrCN}_{2} \mathrm{CO}_{2} \mathrm{Et}$ & $80-90$ & Schöllkopf et al. 1968 \\
\hline & $\mathrm{Hg}\left(\mathrm{CN}_{2} \mathrm{CO}_{2} \mathrm{Et}\right)_{2}$ & $\mathrm{I}_{2}, 0{ }^{\circ} \mathrm{C}$ & $\mathrm{ICN}_{2} \mathrm{CO}_{2} \mathrm{Et}$ & $70-90$ & $\begin{array}{c}\text { Schöllkopf et al. } 1968 \\
\text { Gerhart et al. } 1967\end{array}$ \\
\hline Nitration & $\mathrm{HCN}_{2} \mathrm{CO}_{2} \mathrm{Et}$ & $\begin{array}{c}\mathrm{N}_{2} \mathrm{O}_{5}, \mathrm{CCl}_{4} \\
-30{ }^{\circ} \mathrm{C}\end{array}$ & $\mathrm{O}_{2} \mathrm{NCN}_{2} \mathrm{CO}_{2} \mathrm{Et}$ & ---- & Schöllkopf et al. 1969 \\
\hline Alkylation & $\mathrm{AgCN}_{2} \mathrm{CO}_{2} \mathrm{Et}$ & $\begin{array}{c}\mathrm{H}_{2} \mathrm{C}=\mathrm{CHCH}_{2} \mathrm{I} \\
\text { ether, } 0{ }^{\circ} \mathrm{C}\end{array}$ & $\mathrm{H}_{2} \mathrm{C}=\mathrm{CHCH}_{2} \mathrm{CN}_{2} \mathrm{CO}_{2} \mathrm{Et}$ & 66 & $\begin{array}{l}\text { Schöllkopf and } \\
\text { Rieber } 1969\end{array}$ \\
\hline
\end{tabular}




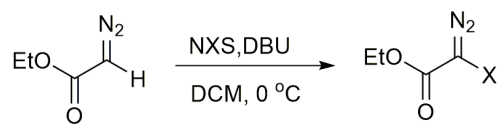

$$
\begin{aligned}
& \mathrm{X}=\mathrm{Cl}, \mathrm{Br} \text { or } \mathrm{I}
\end{aligned}
$$

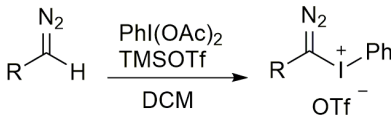

$$
\begin{aligned}
& \text { i. } \mathrm{Bu}_{4} \mathrm{NX}, \mathrm{DCM} \\
& \text { ii. } \mathrm{KX}, \mathrm{H}_{2} \mathrm{O} / \mathrm{DCM} \\
& \text { iii. } \mathrm{KX}, 18 \text {-crown-6, DCM } \\
& {\stackrel{\mathrm{N}}{\mathrm{N}_{2}}}_{\mathrm{X}} \\
& \mathrm{X}=\mathrm{Cl}, \mathrm{Br} \text { or } \mathrm{I}
\end{aligned}
$$

Figure 45 - Halogenation of diazocetates.
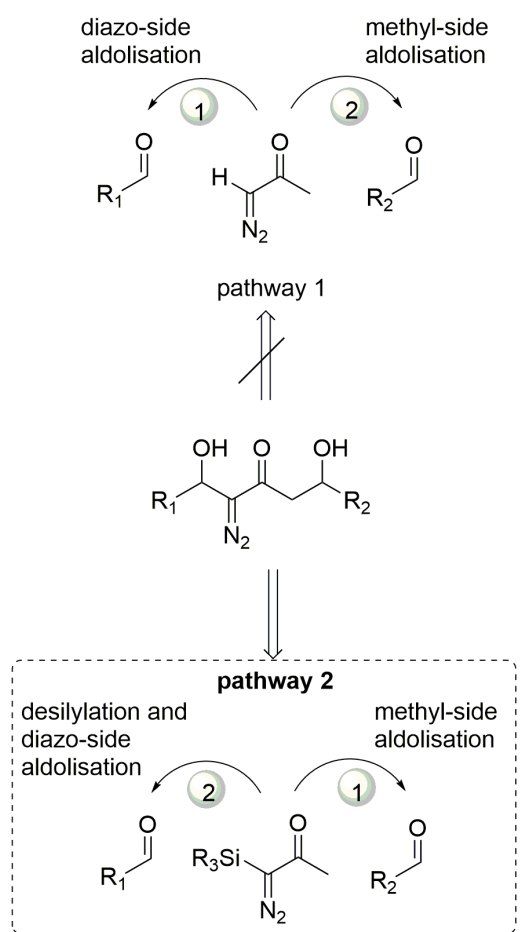

Figure 46 - Substitution of $\alpha$-hydrogen by silyl group as strategy for the bisaldolization of diazoketone.

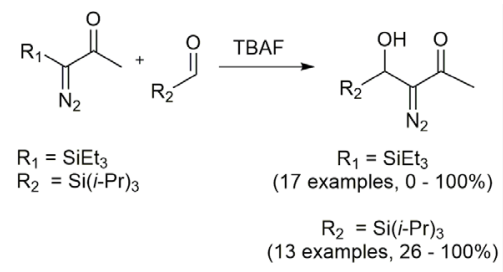

Figure 47 - TBAF-Induced Aldol-Type Addition of TESDiazoacetone and Mukaiyama Aldol-Type Addition of TIPSdiazoacetone to a range of Aldehydes.
(LDA), butyllithium, sodium hydride, potassium hexamethyl disilyl amide (KHMDS), or $\mathrm{NaOH}$. The generated anion species adds to ketones, aldehydes and imines to give $\alpha$-diazo- $\beta$-hydroxy or $\beta$-amino carbonyl compounds (Zhang and Wang 2009). Wang and co-workers developed more straightforward reaction conditions for this nucleophilic addition employing catalytic amount of weaker bases such as DBU (Jiang and Wang 2002, Xiao et al. 2007). Moreover, DBU has also been employed in one pot synthesis of the $\alpha$-diazo$\beta$-dicarbonyl compounds as an alternative to the two-step sequence in which the resulting $\alpha$-diazo$\beta$-hydroxycarbonyl adducts were oxidized with IBX or Dess-Martin periodinane (Erhunmwunse and Steel 2008, Li et al. 2008) (Figure 48). The base-mediate addition of diazocarbonyls to electron-deficient imines such as $N$-acyl, $N$-tosyl and $N$-sulfonyl imines has also been reported to provide the corresponding $\beta$-amino $\alpha$-diazo carbonyl derivatives (Jiang et al. 2003, Zhao et al. 2004, 2005, Zhao and Wang 2005) (Figure 48).

Recently, Heydari and co-workers have developed a green method for the synthesis of $\alpha$-diazocarbonyl compounds using deep eutectic solvent (DES) as dual solvent/catalyst in the aldoltype coupling reactions. The use of DES was advantageous because it is accessible, inexpensive and efficient, and also avoid the use of toxic solvents or hazardous catalysts (Miraki et al. 2017) (Figure 49).

The C-C coupling of terminal diazocarbonyl has also been described with other electrophiles, in addition to aldehydes and imines. CuevasYañez and co-workers described the reaction between $\alpha$-diazocarbonyl and methylmagnesium bromide at $-78{ }^{\circ} \mathrm{C}$ generating the corresponding $\alpha$-diazo-bromomagnesium species, which could be reacted with various electrophilic reagents such as chloroformates, pyrocarbonates and sulfonyl chlorides (Cuevas-Yañez et al. 2004) (Figure 50). 


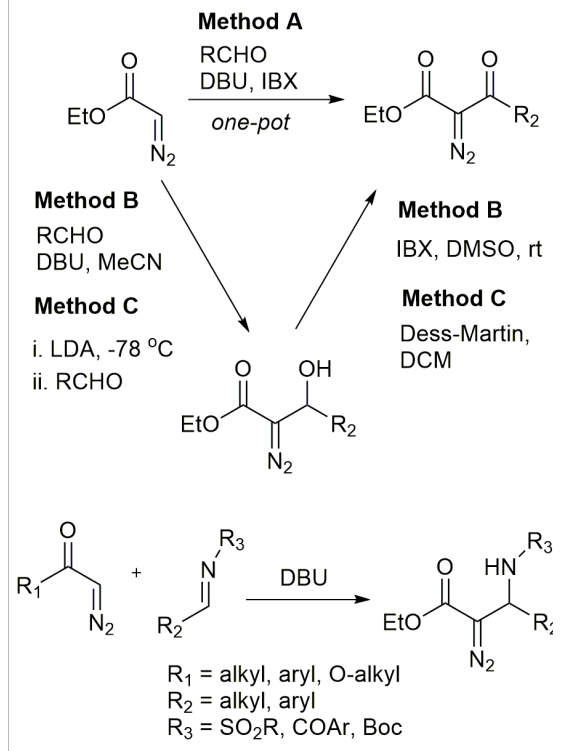

Figure 48 - Base-mediated Aldol-type additions with $\alpha$-diazocarbonyl compounds.

Furthermore, imidazolides have also been described as electrophiles in coupling reactions with $\alpha$-diazocarbonyl compounds. For example, $N$-protected amino acids were converted to $\alpha$-diazoketones, which were coupled with acyl imidazolide in the presence of LDA to afford the corresponding bis $(N$-protected $\alpha$-amino $)$ diazo- $\alpha$ diketones (Saraireh 2012) (Figure 51).

The asymmetric versions of the coupling reactions with diazocarbonyls have also been studied (Zhang and Wang 2009). Wang and Yao investigated the reaction of ethyl diazoacetate with aldehydes under different chiral Lewis acid catalysts. The products were obtained with moderate to good enantioselectivity when $\mathrm{Zr}(\mathrm{IV})$ catalysts and $(S)-6,6-\mathrm{Br}_{2}$-BINOL ligands were used in the aldol reactions (Yao and Wang 2003). A chiral phase-transfer catalyst for the aldehyde coupling reaction with tert-butyl diazoacetate was developed by Nishida and co-workers. In this case, a cinchonidinium salt was used as the chiral catalyst, but there was no improvement in the enantioselectivity of the reactions (Hasegawa et al. 2006). The highest enantioselectivity was

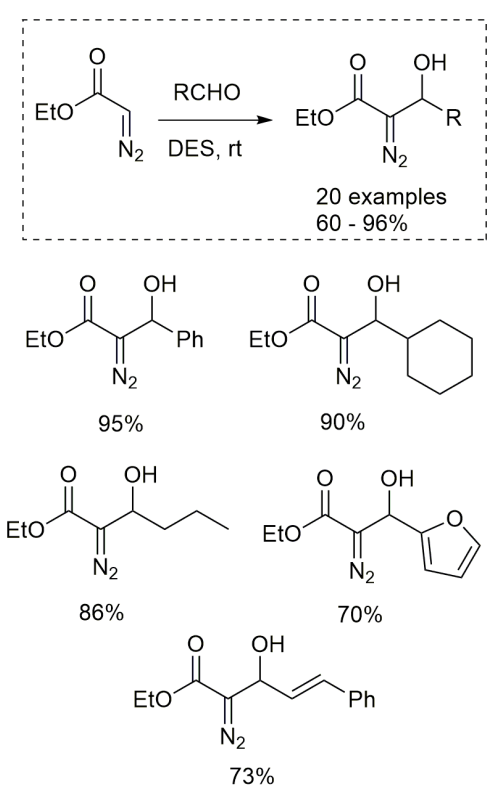

Figure 49 - Aldol-type coupling of $\alpha$-diazocarbonyl compounds using deep eutectic solvent (DES) as dual solvent/ catalyst.

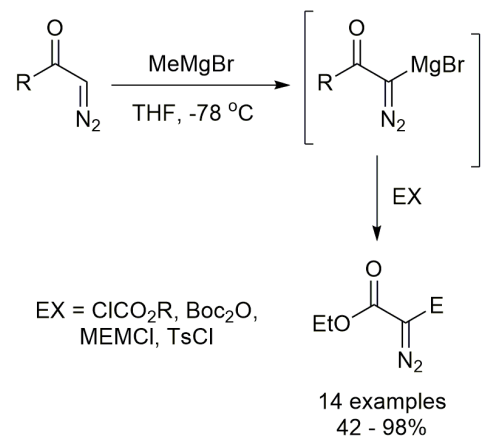

Figure 50 - The C-C coupling of the terminal diazocarbonyl with other electrophiles.

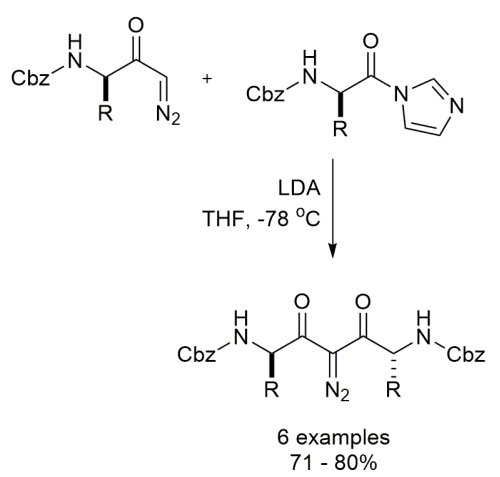

Figure 51 - The coupling reaction between acyl imidazolide and $\alpha$-diazoketones. 


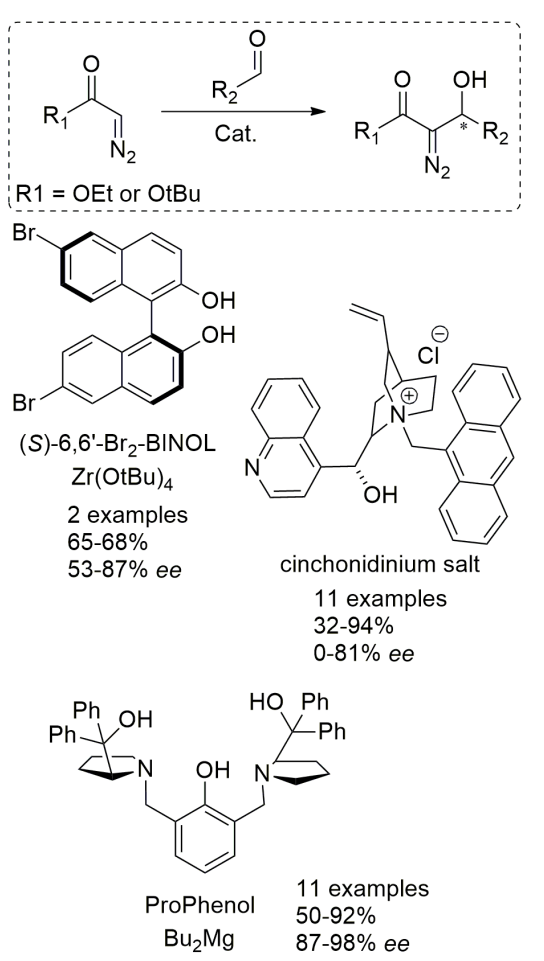

Figure 52 - Asymmetric aldol reaction of diazoketoesters.
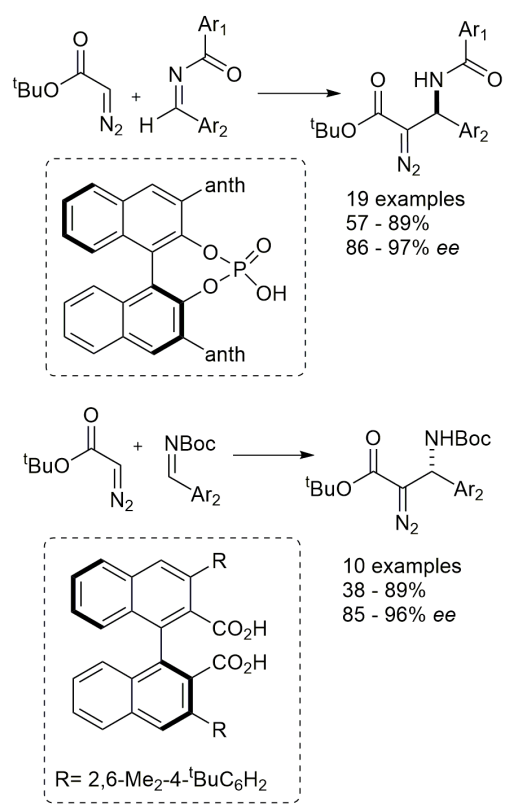
$38-89 \%$ $85-96 \%$ ee

Figure 53 - Asymmetric coupling reaction of diazoketoesters with imines.

achieved by Trost and co-workers using a dinuclear magnesium complex for the direct aldol addition of ethyl diazoacetate to aromatic, aliphatic, and

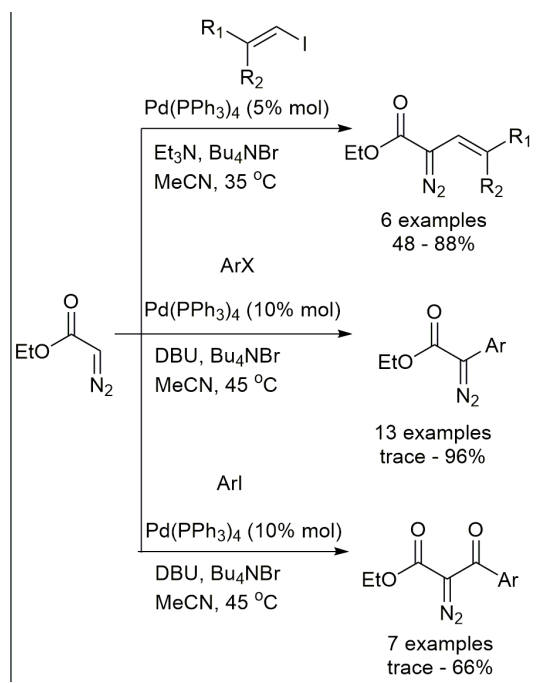

Figure 54 - Palladium-catalyzed cross-coupling of vinyl or aryl iodides/ Carbonylative coupling of aryl Iodides with ethyl diazoacetate.

$\alpha, \beta$-unsaturated aldehydes (Trost et al. 2009, 2012) (Figure 52).

Terada and co-workers reported an asymmetric $\mathrm{C}-\mathrm{N}$ bond formation employing chiral binaphthol monophosphoric acid as catalyst in the coupling reaction between ethyl diazoacetate and acyl imine (Uraguchi et al. 2005). Some years later, Maruoka and Hashimoto published a novel axially chiral dicarboxylic acid for asymmetric Mannich reactions of diazo compounds with arylaldehyde $N$-Boc imines (Hashimoto and Maruoka 2007) (Figure 53).

Another process for the formation of $\mathrm{C}-\mathrm{C}$ bonds consists of palladium-catalyzed crosscoupling reactions. Wang's group showed that ethyl diazoacetate undergoes Pd-catalyzed crosscoupling with aryl or vinyl iodides under relatively mild conditions to generate unsaturated diazoesters. In addition, $\beta$-keto $\alpha$-diazo carbonyl compounds were afforded in moderate yields when the reactions were carried out under a $\mathrm{CO}$ atmosphere (Peng et al. 2007) (Figure 54). 


\section{SUBSTITUENT MODIFICATION IN DIAZOCARBONYL COMPOUNDS}

The diazo group is usually introduced only at the end of a targeted synthesis because this function is highly reactive under several conditions. However, there are limited number of examples that the diazocarbonyl compounds can be modified without affecting the diazo functionality. Bestman and Soliman prepared a diazoacetyl chloride as a diazoacetylation reagent, which reacted with nucleophiles in the presence of weak bases to give the corresponding adducts (Bestman and Soliman 1979). Diazomalonyl chloride was prepared from the reaction of phosgene with diazomethane or reaction of diazoacetic acid with tretrametyl- $\alpha$ chloroenamine (Bestman and Soliman 1979, Devos et al. 1979). Another diazoacylation protocol was proposed by Badet and co-workers in which very stable succinimidyl diazoacetate was used for the direct diazocetylation of amines, phenols, thiophenol and peptides (Ouihia et al. 1993). Padwa and co-workers described the use of ethyl 2-diazomaalonyl chloride in the diazoacetylation reaction with different nucleophiles to afford a variety of diazocarbonyl compounds (Marino et al. 1994) (Figure 55).

Recently, our group showed that the $\alpha, \beta$ unsaturated diazoketones can be modified to another diazocarbonyl derivative by Michael addition with a broad range of amines, remaining intact the diazo functional group for the next transformation (Burtoloso et al. 2015, Dias et al. 2017) (Figure 56). $\alpha, \beta$-unsaturated diazoketones could also be functionalized by means of a Sharpless Asymmetric dihydroxylation to furnish $\alpha, \beta$ dihydroxy diazoketones, an interesting substrate for the short synthesis of substituted furanones (Talero and Burtoloso 2017).

Vinyldiazoesters have also demonstrated to be versatile intermediates for functional modification of diazocarbonyl compounds. Wang and co-

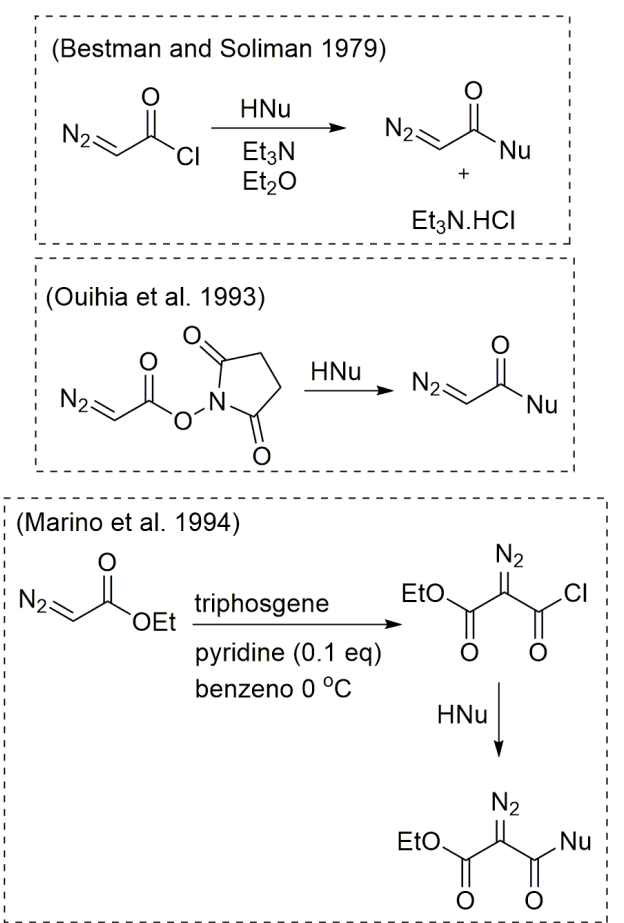

Figure 55 - Diazoacetylation reaction with diazocarbonyl compounds.

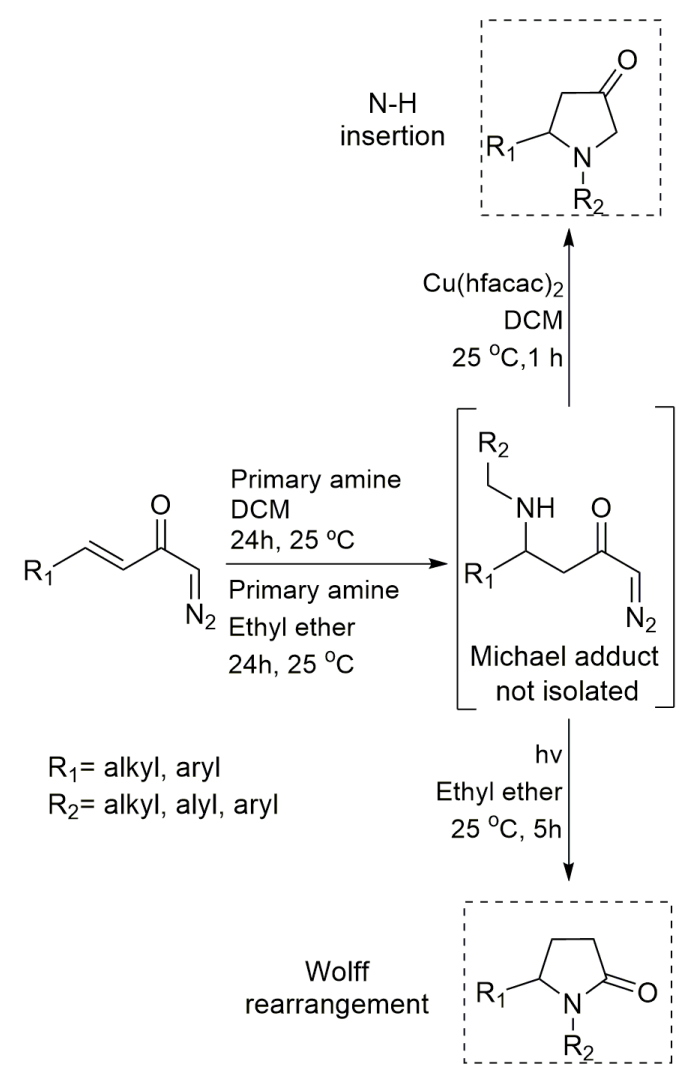

Figure 56 - One pot synthesis of 2 and 3-pyrrolidines from $\alpha, \beta$-unsaturated diazoketones. 
workers proposed an efficient and mild condition to prepare a cyclic vinyl diazo carbonyl compound employing the combination of trifluoroacetic anhydride and triethylamine for the dehydration of $\alpha$-diazo- $\beta$-hydroxy carbonyl derivatives (Shi et al. 2004). Similar reaction conditions were used by Ferreira and co-workers in the preparation of vinyldiazoacetic acid esters of carbohydrate acetonides (Rianelli et al. 2006). These vinyldiazoesters were used as a scaffold for further functionalization of a diazocarbonyl compound. For example, Barluenga and co-workers reported the preparation of $\beta$-oxodiazo derivatives from a copper(II)-catalyzed reaction of alkenyldiazo with iodosylbenzene, involving an unprecented 1,2-shift of the diazoacetate function (Barluenga et al. 2011). Other application of vinyldiazoesters was described by Katukojvala and co-workers in formylation reactions using Vilsmeier reagent to afford enal diazocarbonyl compounds. These compounds were employed in a rhodium-catalyzed benzannulation of pyrroles, leading to substituted indoles (Dawande et al. 2014). Finally, Liu and coworkers used alkenyldiazoesters in a triflic acidcatalyzed Povarov reaction to give diazo-containing cycloadducts stereoselectively, allowing the preparation of various six- and seven-membered azacycles (Jadhav et al. 2012) (Figure 57).

Another class of diazocarbonyls that have been used as a versatile building block are the silyl enol ethers of diazoacetates. Karady and co-workers reported the use of silyl enol diazoacetate in a silver-mediate coupling reaction with 1-( $t$-butyldimethylsilyl)-4-chloro-azetidin2-one to furnish thienamycin precursor (Karady et al. 1981). A similar approach was used to synthetize a variety of carbapenem precursors in which the 4-acetoxyazetin-2-one was employed as the alkylating agent and zinc chloride as coupling reagent (Reider et al. 1982, Reider and Grabowski 1982). Davies and co-workers have showed that a cyclopropanation of vinyl ether with

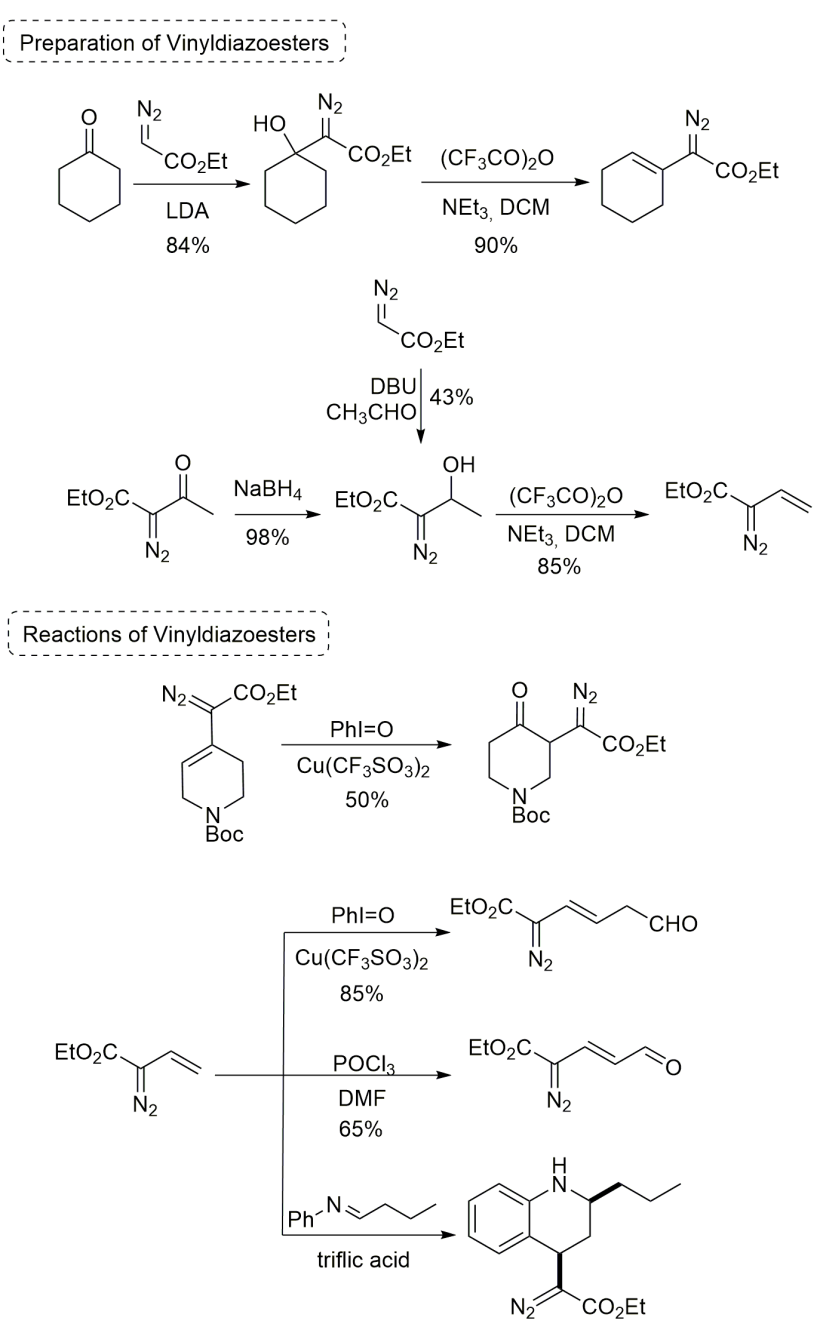

Figure 57 - Preparation and reaction of vinyldiazoesters.

rhodium(II)-stabilized vinylcarbenoids to generate vinylcyclopropanes followed by a $\mathrm{Et}_{2} \mathrm{AlCl}$ catalyzed 1,3-sigmatropic rearrangement resulted in a highly stereoselective $3+2$ annulation (Davies and $\mathrm{Hu}$ 1992). In addition, they reported a combined $\mathrm{C}-\mathrm{H}$ insertion/Cope rearrangement as results of the reaction of vinyldiazoacetates with cyclohexadiene and the synthetic application of this transformation in the formal asymmetric synthesis of $(+)$-sertraline (Davies et al. 1999). Doyle and co-workers have investigated a range of synthetic transformations using silyl enol diazoacetates. They performed a Lewis acid-catalyzed Mukaiyama aldol addition of methyl 3-(trialkylsilanyloxy)-2-diazo-3-butenoate 
with aromatic and aliphatic aldehydes as well as the asymmetric version using $\mathrm{AgF} /(\mathrm{R})$-BINAP as catalyst or using dibutylboron triflate in a high diastereoselectivity reactions with $\alpha$-diazo$\beta$-ketopentanoate (Doyle et al. 2005, Kundu and Doyle 2006, Zhou and Doyle 2010). Moreover, Doyle's group explored the Mukaiyama-Michael reactions with $\alpha, \beta$-enones (Liu et al. 2008, Truong et al. 2012), and Mannich reactions with nitrones and hydrazones (Xu et al. 2011, 2012). More recently, they developed an efficient approach for a Lewis acid mediated coupling reaction of enoldiazo compounds and propargyl acetates to afford a diverse series of alkynyl-tethered diazoketones that undergo a metal-catalyzed carbene metathesis cascade reactions (Qian et al. 2013). Some representative reactions with of enol diazoacetates are shown in Figure 58.

Another example of the versatility of enol diazoacetates can also be seen in cycloaddition reactions (Cheng et al. 2017). These compounds can react in different cycloaddition pathways to construct several carbocycles and heterocycles (Jadhav et al. 2012, Xu et al. 2013, Cheng et al. 2015, 2017, Deng et al. 2016). For example, Enol Silyl Ether (ESE) unit of enoldiazo compounds can undergo $[2+n]$-cycloadditions $(n=3,4)$ to provide $\alpha$-cyclic- $\alpha$-diazo compounds with retention of the diazo group (ESEC pathway). In addition, MetalloEnolCarbenes (MEC) formed by dinitrogen extrusion from enoldiazo compounds can participate in transition metalcatalyzed $[3+n]$-cycloadditions $(\mathrm{n}=1-5)$ as three-carbon synthons (MECC pathway). Finally, donor-acceptor CycloPropEnes (CPE) generated in situ from enoldiazo compounds can produce cyclopropane-fused ring systems by $[2+n]$-cycloadditions $(n=3,4)$ (CPEC pathway) (Cheng et al. 2017) (Figure 59). Further studies covering the application of cycloaddition reactions with enoldiazo compounds in the syntheses of natural products and pharmaceutical analogues are the next prospects.

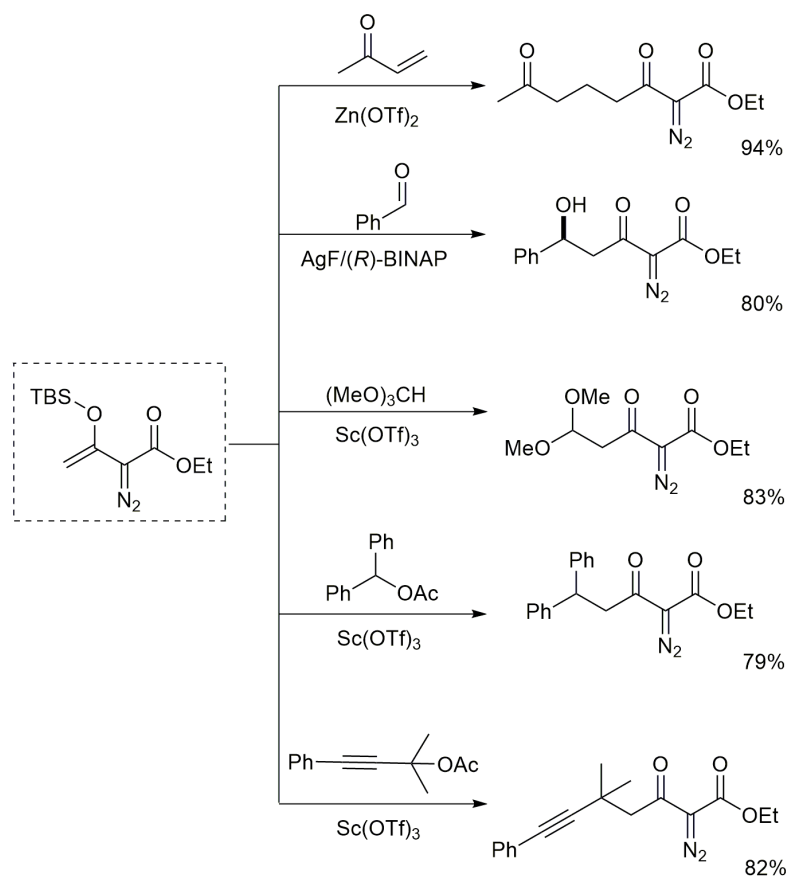

Figure 58 - Application of the silyl enol ethers of diazoacetates.

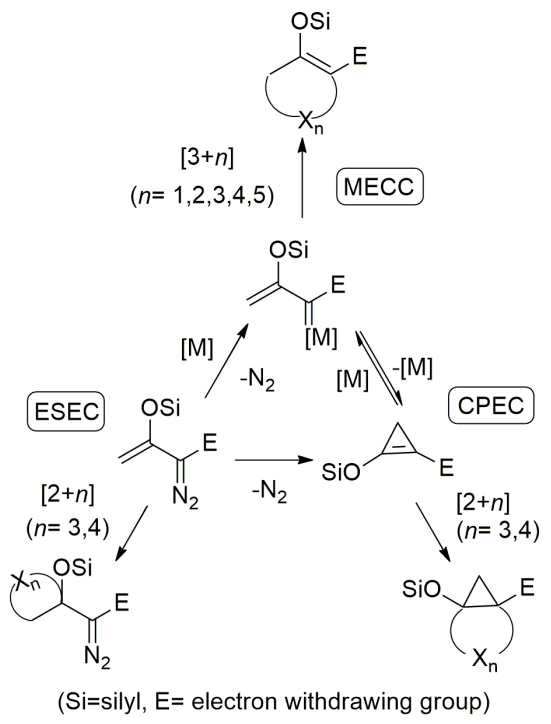

Figure 59 - Different cycloadditions pathways of enoldiazo compounds.

\section{CONCLUSION}

Diazocarbonyl compounds can undergo a wide range of synthetic transformations and, because of this, several researchers have investigated their preparation, reactivity and application through 
the years. We summarize in this review the classical approaches to the preparation of these compounds as well as the main improvements and innovations in this chemistry. The most significant developments in diazomethane acylation have been done regarding the safer preparation of diazomethane using the continuous flow conditions. For diazo transfer reactions, efforts were done in the development of novel sulfonyl azide reagents and mild reaction conditions. Other advances involved the transformation of already prepared diazocarbonyl compounds into more complex ones, without loss of the diazo functionality. They include substitution reactions with a wide range of electrophiles, chemoselective oxidation of the $\beta$-hydroxyl group in diazo compound, crosscoupling at the diazo function, and the use of vinyldiazoacetates and silyl enol diazoacetates.

\section{ACKNOWLEDGMENTS}

We would thank Fundação de Amparo à Pesquisa do Estado de São Paulo (FAPESP) for financial support (2013/25504-1; 2013/18009-4) and fellowship to P. B. M. (2015/22003-7). We also thank Conselho Nacional de Desenvolvimento Científico e Tecnológico (CNPq) for a research fellowship to A.C.B.B. (303437/2015-4) a fellowship to G.L.N. (130528/2017-0).

\section{REFERENCES}

ABID I, GAVELLE S, CHANY AC, LEGROS F, GOSSELIN P, ABID S, DUJARDIN G AND GAULON-NOURRY C. 2017. Advances in the TBAF-induced aldol-type addition of $\alpha$-trialkylsilyl- $\alpha$-diazoacetones: TIPS versus TES. C R Chimie 20: 595-600.

ABID I, GOSSELIN P, MATHÉ-ALLAINMAT M, ABID S, DUJARDIN G AND GAULON-NOURRY C. 2015. TBAF-Triggered aldol-type addition of $\alpha$-triethylsilyl- $\alpha$ diazoacetone. J Org Chem 80: 9980-9988.

ALlER E, MOLINA P AND LORENZO Á. 2000. N-Isocyanotriphenyliminophosphorane; a convenient reagent for the conversion of acyl chlorides into $\alpha$-diazoketones. Synlett, p. 526-528.
ARNDT F AND AMENDE J. 1928. Synthesen mit diazomethan, V.: Über die reaktion der säurechloride mit diazomethan. Ber Dtsch Chem Ges B Ser 61: 1122-1124.

ARNDT F, EISTERT B AND AMENDE J. 1928. Nachträge zu den synthesen mit diazo-methan. Ber Dtsch Chem Ges B Ser 61: 1949-1953.

ARNDT F, EISTERT B AND PARTALE W. 1927. Diazomethan und O-nitroverbindungen, II.: N-oxyisatin aus O-nitro-benzoylchlorid. Ber Dtsch Chem Ges B Ser 60: 1364-1370.

BAMFORD WR AND STEVENS TS. 1952. The decomposition of toluene-p-sulphonylhydrazones by alkali. J Chem Soc, p. 4735-4740.

BARLUENGA J, LONZI G, RIESGO L, TOMÁS M AND LÓPEZ LA. 2011. Direct access to $\beta$-oxodiazo compounds by copper(II)-catalyzed oxidative rearrangement of stabilized vinyl diazo derivatives. J Am Chem Soc 133: 18138-18141.

BAUM JS, SHOOK DA, DAVIES HML AND SMITH HD. 1987. Diazotransfer reactions with p-acetamidobenzenesulfonyl azide. Synth Commun 17: 1709-1716.

BAUMGART RJ. 1967. Preparation of ethyl diazoacetate via a triazene intermediate. J Org Chem 32: 484-485.

BERNARDIM B AND BURTOLOSO ACB. 2014. A two-step synthesis of the bioprotective agent JP4-039 from N-BocL-leucinal. Tetrahedron 70: 3291-3296.

BERNARDIM B, LORDELLO L AND BURTOLOSO ACB. 2013. $\alpha, \beta$-unsaturated diazoketones as versatile building blocks for the synthesis of hydroxylated piperidines, indolizidines and quinolizidines. Curr Top Med Chem 13: 2099-2103.

BERNARDIM B, PINHO VD AND BURTOLOSO ACB. 2012. $\alpha, \beta$-unsaturated diazoketones as platforms in the asymmetric synthesis of hydroxylated alkaloids. Total synthesis of 1-deoxy-8,8a-diepicastanospermine and 1,6-dideoxyepicastanospermine and formal synthesis of pumiliotoxin 251D. J Org Chem 77: 9926-9931.

BESTMANN HJ AND SOLIMAN FM. 1979. Synthesis and reactions of diazoacetyl chloride - detection of diazoketene. Angew Chem Int Ed Engl 18: 947-948.

BRADLEY W AND ROBINSON R. 1928. The interaction of benzoyl chloride and diazomethane together with a discussion of the reactions of the diazenes. J Chem Soc 1310-1318.

BURTOLOSO ACB, DIAS RMP AND BERNARDIM B. 2015. $\alpha, \beta$-Unsaturated diazoketones as useful platforms in the synthesis of nitrogen heterocycles. Acc Chem Res 48: 921-934.

CALLANT P, D'HAENENS L AND VANDEWALLE M. 1984. An efficient preparation and the intramolecular cyclopropanation of $\alpha$-diazo- $\beta$-ketophosphonates and $\alpha$-diazophosphono-acetates. Synth Commun 14: 155-161. 
CHALLIS BC AND LATIF F. 1990. Synthesis and characterisation of some new diazopeptides. J Chem Soc Perkins Trans, p. 1005-1009.

CHANG SJ, SHANKAR BKR AND SHECHTER H. 1982. Chemistry of diazoacenaphthenones and diazoacenaphthenes. J Org Chem 47: 4226-4234.

CHARETTE AB, WURZ RP AND OLLEVIER T. 2000. Trifluoromethanesulfonyl azide: a powerful reagent for the preparation of $\alpha$-nitro- $\alpha$-diazocarbonyl derivatives. $J$ Org Chem 65: 9252-9254.

CHENG QQ, DENG Y, LANKELMA M AND DOYLE MP. 2017. Cycloaddition reactions of enoldiazo compounds. Chem Soc Rev 46: 5425-5443.

CHENG QQ, QIAN Y, ZAVALIJ PY AND DOYLE MP. 2015. Lewis acid/rhodium-catalyzed formal [3+3]-cycloaddition of enoldiazoacetates with donor-acceptor cyclopropanes. Org Lett 17: 3568-3571.

CHIARA JL AND SUÁREZ JR. 2011. Synthesis of $\alpha$-diazo carbonyl compounds with the shelf-stable diazo transfer reagent nonafluorobutanesulfonyl azide. Adv Synth Catal 353: 575-579.

CHOU H AND RAINES RT. 2013. Conversion of azides into diazo compounds in water. J Am Chem Soc 135: 1493614939.

CLIVE DLJ AND DAIGNEAULT S. 1991. Use of radical ring opening for introduction of alkyl and substituted alkyl groups with stereochemical control: a synthetic application of cyclopropylcarbinyl radicals. J Org Chem 56: 38013814.

COATES RM AND KANG HY. 1987. Synthesis and evaluation of cyclobutylcarbinyl derivatives as potential intermediates in diterpene biosynthesis. J Org Chem 52: 2065-2074.

COREY EJ AND MYERS AG. 1984. Efficient synthesis and intramolecular cyclopropanation of unsaturated diazoacetic esters. Tetrahedron Lett 25: 3559-3562.

COSTIN TA, DUTRA LG, BORTOLUZZI AJ AND SÁ MM. 2017. Amine-mediated synthesis of amides from 1,3-dicarbonyl compounds through a domino diazo transfer/aminolysis process. Tetrahedron 73: 4549-4559.

CUEVAS-YAÑEZ E, GARCÍA MA, DE LA MORA MA, MUCHOWSKI JM AND CRUZ-ALMANZA R. 2003. Novel synthesis of $\alpha$-diazoketones from acyloxyphosphonium salts and diazomethane. Tetrahedron Lett 44: 4815-4817.

CUEVAS-YAÑEZ E, MUCHOWSKI JM AND CRUZALMANZA R. 2004. Metalation of $\alpha$-diazocarbonyl compounds using grignard reagents. A convenient synthesis of $\alpha$-diazo- $\beta$-ketoesters and mixed esters of $\alpha$-diazomalonate. Tetrahedron Lett 45: 2417-2419.

CURPHEY TJ AND DANIEL DS. 1978. New synthesis of azaserine. J Org Chem 43: 4666-4668.
CURTIUS T. 1883. Ueber die einwirkung von salpetriger saure auf salzsauren glycocollather. Ber Dtsch Chem Ges 16: $2230-2231$.

DALLINGER D, PINHO VD, GUTMANN B AND KAPPE CO. 2016. Laboratory-scale membrane reactor for the generation of anhydrous diazomethane. J Org Chem 81: 5814-5823.

DANHEISER RL, MILLER RF AND BRISBOIS RG. 1996. Detrifluoroacetylative diazo group transfer: (E)-1-diazo-4phenyl-3-buten-2-one. Org Synth 73: 134-143.

DANHEISER RL, MILLER RF, BRISBOIS RG AND PARK SZ. 1990. An improved method for the synthesis of $\alpha$-diazo ketones. J Org Chem 55: 1959-1964.

DAVIES HML AND HU B. 1992. Highly stereoselective [3 +2 ] annulations by cyclopropanation of vinyl ethers with rhodium(II)-stabilized vinylcarbenoids followed by a formally forbidden 1,3-sigmatropic rearrangement. J Org Chem 57: 3186-3190.

DAVIES HML, STAFFORD DG AND HANSEN T. 1999. Catalytic asymmetric synthesis of diarylacetates and 4,4-diarylbutanoates. A formal asymmetric synthesis of (+)-sertraline. Org Lett 1: 233-236.

DAWANDE SG, KANCHUPALLI V, KALEPU J, CHENNAMSETTI H, LAD BS AND KATUKOJVALA S. 2014. Rhodium enalcarbenoids: direct synthesis of indoles by rhodium(II)-catalyzed [4 +2 ] benzannulation of pyrroles. Angew Chem Int Ed 53: 4076-4080.

DE BOER TJ AND BACKER HJ. 1963. Diazomethane. Org Synth Coll Vol 4, Rabjohn N Ed. New York: J Wiley \& Sons, New York, USA, p. 250-253.

DEADMAN BJ, O'MAHONY RM, LYNCH D, CROWLEY DC, COLLINS SG AND MAGUIRE AR. 2016. Taming tosyl azide: the development of a scalable continuous diazo transfer process. Org Biomol Chem 14: 3423-3431.

DENG Y, PEI C, ARMAN H, DONG K, XU X AND DOYLE MP. 2016. Syntheses of tetrahydropyridazine and tetrahydro-1,2-diazepine scaffolds through cycloaddition reactions of azoalkenes with enol diazoacetates. Org Lett 18: 5884-5887.

DEVOS A, REMION J, FRISQUE-HESBAIN AM, COLENS AAND GHOSEZ L. 1979. Synthesis of acyl halides under very mild conditions. J Chem Soc, Chem Commun, p. 1180-1181.

DEWALD HA AND MOORE AM. 1958. 6-Diazo-5-oxo-Lnorleucine, a new tumor inhibitory substance. Preparation of L-, D- and DL-forms. J Am Chem Soc 80: 3941-3945.

DIAS RMP, MOMO PB AND BURTOLOSO ACB. 2017. One-step syntheses of substituted 2-pyrrolidinones and 3 -pyrrolidinones from $\alpha, \beta$-unsaturated diazoketones and amines. Application in the synthesis of barmumycin. Tetrahedron 73: 3720-3729.

DIMROTH O. 1910. Über intramolekulare umlagerungen. Ann Chem 373: 336-370. 
DOYLE MP, DOROW RL, TERPSTRA JW AND RODENHOUSE RA. 1985. Synthesis and catalytic Reaction of chiral N-(diazoacetyl)oxazolidones. J Org Chem 50: 1663-1666.

DOYLE MP AND KALININ AV. 1996. Highly enantioselective intramolecular cyclopropanation reactions of $\mathrm{N}$ allylic-N-methyldiazoacetamides catalyzed by chiral dirhodium(II) carboxamidates. J Org Chem 61: 2179-2184.

DOYLE MP, KUNDU K AND RUSSELL AE. 2005. Catalytic addition methods for the synthesis of functionalized diazoacetoacetates and application to the construction of highly substituted cyclobutanones. Org Lett 7: 5171-5174.

DOYLE MP, MCKERVEY MA AND YE T. 1998. Modern catalytic methods for organic synthesis with diazo compounds: from cylclopropanes to ylides. New York: J Wiley \& Sons, New York, USA, 652 p.

DUTRA LG, SAIBERT C, VICENTINI DS AND SÁ MM. 2014. Diazo transfer reaction to 1,3-dicarbonyl compounds with sulfonyl azides catalyzed by molecular sieves. J Mol Catal A: Chem 386: 35-41.

ERHUNMWUNSE MO AND STEEL PG. 2008. A simple one-pot preparation of diazoacetoacetate derivatives from aldehydes. J Org Chem 73: 8675-8677.

FAISAL S, ZANG Q, MAITY PK, BRANDHOFER A, KEARNEY PC, REISER O, GRASS RN, STOIANOVA D AND HANSON PR. 2017. Development and application of a recyclable high-load magnetic $\mathrm{Co} / \mathrm{C}$ hybrid ROMPderived benzenesulfonyl chloride reagent and utility of corresponding analogues. Org Lett 19: 2274-2277.

FANG FG, MAIER ME AND DANISHEFSKY SJ. 1990. New routes to functionalized benzazepine substructures: a novel transformation of an alpha-diketone thioamide induced by trimethyl phosphite. J Org Chem 155: 831-838.

FINK J AND REGITZ M. 1985. Electrophilic diazoalkane substitution. Synthesis, p. 569-585.

FISCHER N, GODDARD-BORGER ED, GREINER R, KLAPÖTKE TM, SKELTON BW AND STIERSTORFER J. 2012. Sensitivities of some imidazole-1-sulfonyl azide salts. J Org Chem 77: 1760-1764.

FORD A, MIEL H, RING A, SLATTERY CN, MAGUIRE AR AND MCKERVEY MA. 2015. Modern organic synthesis with $\alpha$-diazocarbonyl compounds. Chem Rev 115: 998110080 .

FORSTER MO. 1915. Azotisation by chloroamine. J Chem Soc 107: 260-267.

FURROW ME AND MYERS AG. 2004. A general procedure for the esterification of carboxylic acids with diazoalkanes generated in situ by the oxidation of $\mathrm{N}$-tertbutyldimethylsilylhydrazones with (difluoroiodo)benzene. J Am Chem Soc 126: 12222-12223.

GERHART F, SCHÖLLKOPF U AND SCHUMACHER H. 1967. Ethyl diazoiodoacetate and its decomposition to ethoxycarbonyliodocarene. Angew Chem Int Ed Engl 6: 74-75.
GODDARD-BORGER ED AND STICK RV. 2007. An efficient, inexpensive, and shelf-stable diazo transfer reagent: imidazole-1-sulfonyl azide hydrochloride. Org Lett 9: 3797-3800.

GREEN GM, PEET NP AND METZ WA. 2001. Polystyrenesupported benzenesulfonyl azide: a diazo transfer reagent that is both efficient and safe. J Org Chem 66: 2509-2511.

GRUNDMANN C. 1936. Ein neues verfahren zur überführung von carbonsäuren in aldehyde. Justus Liebigs Ann Chem 524: $31-48$.

GUTMANN B, CANTILLO D AND KAPPE CO. 2015. Continuous-flow technology-a tool for the safe manufacturing of active pharmaceutical ingredients. Angew Chem Int Ed 54: 6688-6728.

HARMON RE, SOOD VK AND GUPTA SK. 1974. A new synthesis of $\alpha, \beta$-unsaturated diazo-Ketones: an improved synthesis of 4-diazo-3-oxo-1-phenyl-1-butene (diazomethyl styryl ketone). Synthesis, p. 577-578.

HARNED AM, SHERRILL WM, FLYNN DL AND HANSON PR. 2005. High-load, soluble oligomeric benzenesulfonyl azide: application to facile diazo-transfer reactions. Tetrahedron 61: 12093-12099.

HASEGAWA K, ARAI S AND NISHIDA A. 2006. Synthesis of $\alpha$-Diazo- $\beta$-hydroxyesters through a one-pot protocol by phase-transfer catalysis: application to enantioselective aldol-type reaction and diastereoselective synthesis of $\alpha$-amino- $\beta$-hydroxyester derivatives. Tetrahedron 62 : 1390-1401.

HASHIMOTO T AND MARUOKA K. 2007. Design of axially chiral dicarboxylic acid for asymmetric Mannich reaction of arylaldehyde $N$-Boc imines and diazo compounds. J Am Chem Soc 129: 10054-10055.

HAZEN GG, BOLLINGER FW, ROBERTS FE, RUSS WK, SEMAN JJ AND STASKIEWICZ S. 1996. 4-dodecylbenzenesulfonyl azides. Org Synth 73: 144-151.

HODSON D, HOLT G AND WALL DK. 1970. Diazoketones from the interaction of diazoalkanes with carboxylic aciddicyclohexyl carbodiimide mixtures. J Chem Soc C, p. 971-973.

HOLTON TL AND SHECHTER H. 1995. Advantageous syntheses of diazo compounds by oxidation of hydrazones with lead tetraacetate in basic environments. J Org Chem 60: 4725-4729.

HOUSE HO AND BLANKLE CJ. 1968. Preparation and decomposition of unsaturated esters of diazoacetic acid. J Org Chem 33: 53-60.

HUDLICKY M. 1980. An improved apparatus for the laboratory preparation of diazomethane. J Org Chem 45: 5377-5378.

HUDLICKY M. 1982. A simplified apparatus for generation of diazomethane. Org Prep Proced Int 14: 354-356.

IRELAND RE, DOW WC, GODFREY JD AND THAISRIVONGS S. 1984. Total synthesis of 
(+-)-aphidicolin and (+-)-beta-chamigrene. J Org Chem 49: 1001-1013.

JADHAV AM, PAGAR VV AND LIU RS. 2012. Development of a Povarov reaction/carbene generation sequence for alkenyldiazocarbonyl compounds. Angew Chem Int Ed 51: 11809-11813.

JAVED MI AND BREWER M. 2007. Diazo preparation via dehydrogenation of hydrazones with 'activated' DMSO. Org Lett 9: 1789-1792.

JIANG N, MA Z, QU Z, XING X, XIE L AND WANG J. 2003. Investigation of the transition-metal- and acidcatalyzed reactions of $\alpha$-(N-tosyl)amino diazo carbonyl compounds. J Org Chem 68: 893-900.

JIANG N AND WANG J. 2002. DBU-promoted condensation of acyldiazomethanes to aldehydes and imines under catalytic conditions. Tetrahedron Lett 43: 1285-1287.

KARADY S, AMATO JS, REAMER RA AND WEINSTOCK LM. 1981. Stereospecific conversion of penicillin to thienamycin. J Am Chem Soc 103: 6765-6767.

KATRITSKY AR AND EL KHATIB M. 2012. Chemical safety: benzotriazole-1-sulfonyl azide. Chem Eng News 90: 4 .

KATRITZKY AR, EL KHATIB M, BOL'SHAKOV O, KHELASHVILI L AND STEEL PJ. 2010. Benzotriazol1-yl-sulfonyl azide for diazotransfer and preparation of azidoacylbenzotriazoles. J Org Chem 75: 6532-6539.

KAUPANG $\AA$ AND BONGE-HANSEN T. 2013. $\alpha$-Bromodiazoacetamides-a new class of diazo compounds for catalyst-free, ambient temperature intramolecular $\mathrm{C}-\mathrm{H}$ insertion reactions. Beilstein J Org Chem 9: 1407-1413.

KENNEDY M AND MCKERVEY MA. 1991. Pseudoguaianolides from intramolecular cycloadditions of aryl diazoketones: synthesis of $( \pm)$-confertin and approach to the synthesis of $( \pm$ )-damsin. J Chem Soc Perkin Trans 1: 2565-2574.

KENNEDY M, MCKERVEY MA, MAGUIRE AR AND ROSS GHP. 1990. Asymmetric synthesis in carbon-carbon bond forming reactions of $\alpha$-diazoketones catalyzed by homochiral rhodium (II) carboxylates. J Chem Soc, Chem Commun, p. 361-362.

KITAMURA M, KATO S, YANO M, TASHIRO N, SHIRATAKE Y, SANDO M AND OKAUCHI T. 2014. A reagent for safe and efficient diazo-transfer to primary amines: 2-azido-1,3-dimethylimidazolinium hexafluorophosphate. Org Biomol Chem 12: 4397-4406.

KITAMURA M, YANO M, TASHIRO N, MIYAGAWA S, SANDO M AND OKAUCHI T. 2011. Direct synthesis of organic azides from primary amines with 2-azido-1,3dimethylimidazolinium hexafluorophosphate. Eur J Org Chem 2011: 458-462.

KUNDU K AND DOYLE MP. 2006. Constructing chiral diazoacetoacetates by enantioselective catalytic
Mukaiyama aldol reactions. Tetrahedron Asymmetr 17: 574-577.

LANCOU A, HAROUN H, KUNDU UK, LEGROS F, ZIMMERMANN N, MATHÉ-ALLAINMAT M, LEBRETON J, DUJARDIN G, GAULON-NOURRY C AND GOSSELIN P. 2012. $\alpha$-Triethylsilyl- $\alpha$-diazoacetone in double cross-aldolisation: convenient acetone equivalent toward 5-hydroxy-1,3-diketones. Tetrahedron 68: 96529657.

LI P, MAJIRECK MM, KORBOUKH I AND WEINREB SM. 2008. A mild, efficient method for the oxidation of $\alpha$-diazo$\beta$-hydroxyesters to $\alpha$-diazo- $\beta$-ketoesters. Tetrahedron Lett 49: 3162-3164.

LIU Y, ZHANG Y, JEE N AND DOYLE MP. 2008. Construction of highly functionalized diazoacetoacetates via catalytic Mukaiyama-Michael reactions. Org Lett 10: 1605-1608.

LOWE G AND YEUNG HW. 1973. Synthesis of a $\beta$-lactam related to the cephalosporins. J Chem Soc Perkin Trans 1: 2907-2910.

MAAS G. 2009. New syntheses of diazo compounds. Angew Chem Int Ed 48: 8186-8195.

MARINO JR JP, OSTERHOUT MH, PRICE AT, SHEEHAN SM AND PADWA A. 1994. Ethyl 2-diazomalonyl chloride. An efficient diazoacylation reagent. Tetrahedron Lett 35: 849-852.

MARTIN LJ, MARZINZIK AL, LEY SV AND BAXENDALE IR. 2011. Safe and reliable synthesis of diazoketones and quinoxalines in a continuous flow reactor. Org Lett 13: 320-323.

MASTRONARDI F, GUTMANN B AND KAPPE CO. 2013. Continuous flow generation and reactions of anhydrous diazomethane using a teflon AF-2400 tube-in-tube reactor. Org Lett 15: 5590-5593.

MAURYA RA, PARK CP, LEE JH AND KIM DP. 2011. Continuous in situ generation, separation, and reaction of diazomethane in a dual-channel microreactor. Angew Chem Int Ed 50: 5952-5955.

MCCAW PG, BUCKLEY NM, ECCLES KS, LAWRENCE SE, MAGUIRE AR AND COLLINS SG. 2017. Synthesis of cyclic $\alpha$-diazo- $\beta$-keto sulfoxides in batch and continuous flow. J Org Chem 82: 3666-3679.

MCCAW PG, DEADMAN BJ, MAGUIRE AR AND COLLINS SG. 2016. Delivering enhanced efficiency in the synthesis of $\alpha$-diazosulfoxides by exploiting the process control enabled in Flow. J Flow Chem 6: 226-233.

MIRAKI MK, MEHRABAN JA, YAZDANI E AND HEYDARI A. 2017. Deep eutectic solvent (DES) as dual solvent/catalyst for synthesis of $\alpha$-diazocarbonyl compounds using aldol-type coupling. J Mol Liq 234: 129-132.

MIX KA, ARONOFF MR AND RAINES RT. 2016. Diazo compounds: versatile tools for chemical biology. Chem Biol 11: 3233-3244. 
MORANDI B AND CARREIRA EM. 2012. Iron-catalyzed cyclopropanation in $6 \mathrm{M} \mathrm{KOH}$ with in situ generation of diazomethane. Science 335: 1471-1474.

MÜLLER STR, MURAT A, HELLIER P AND WIRTH T. 2016. Toward a large-scale approach to milnacipran analogues using diazo compounds in flow chemistry. Org Process Res Dev 20: 495-502.

MÜLLER STR, MURAT A, MAILLOS D, LESIMPLE P, HELLIER P AND WIRTH T. 2015. Rapid generation and safe use of carbenes enabled by a novel flow protocol with in-line IR spectroscopy. Chem Eur J 21: 7016-7020.

MÜLLER STR AND WIRTH T. 2015. Diazo compounds in continuous-flow technology. Chem Sus Chem 8: 245-250.

MUTHYALA MK, CHOUDHARY S AND KUMAR A. 2012. Synthesis of ionic liquid-supported sulfonyl azide and its application in diazotransfer reaction. J Org Chem 77: 8787-8791.

MYERS EL AND RAINES RT. 2009. Diazo Compounds a phosphine-mediated conversion of azides into diazo compounds. Angew Chemie Intenational Ed 48: 23592363.

MYKHAILIUK PK. 2014. Generation of $\mathrm{C}_{2} \mathrm{~F}_{5} \mathrm{CHN}_{2}$ in situ and its first reaction : $[3+2]$ cycloaddition with alkenes. A Eur J 20: 4942-4947.

MYKHAILIUK PK. 2015. Three-component synthesis of fluorinated pyrazoles from fluoroalkylamines, $\mathrm{NaNO}_{2}$ and electron-deficient alkynes. Org Biomol Chem 13: 34383445.

MYKHAILIUK PK. 2017. Heptafluoroisopropyl diazomethane $\left(\mathrm{i}-\mathrm{C}_{3} \mathrm{~F}_{7} \mathrm{CHN}_{2}\right)$ : in situ generation and synthesis of pyrazoles. Org Biomol Chem 15: 7296-7301.

NICOLAOU KC, BARAN PS, ZHONG YL, CHOI HS, FONG KC, HE Y AND YOON WH. 1999. New synthetic technology for the synthesis of hindered $\alpha$-diazoketones via acyl mesylates. Org Lett 1: 883-886.

NIOSH - THE NATIONAL INSTITUTE OF OCCUPATIONAL SAFETY AND HEALTH. 1995. Diazomethane, March 15, 1995 Validated. Available at: https://www.cdc.gov/niosh/ipcsneng/neng 1256.html. Acessed on July 17, 2017.

NISHIMURA M, NAKADA H, TAKASE S, KATAYAMA A, GOTO T, TANAKA H AND HASHIMOTO M. 1988. A new antitumor antibiotic, FR900840. J Antibiot (Tokyo) 42: $549-552$.

OPPOLZER W, BATTIG K AND HUDLICKY T. 1981. A total synthesis of $( \pm)$-isocomene and $( \pm) \beta$-isocomene by an intramolecular ene reaction. Tetrahedron 37: 43594364.

OUIHIAA, RENE L, GUILHEM J, PASCARD CAND BADET B. 1993. A new diazoacylating reagent: preparation, structure, and use of succinimidyl diazoacetate. J Org Chem 58: 1641-1642.

PACE V, VERNIEST G, SINISTERRA JV, ALCÁNTARA AR AND DE KIMPE N. 2010. Improved Arndt-
Eistert synthesis of $\alpha$-diazoketones requiring minimal diazomethane in the presence of calcium oxide as acid scavenger. J Org Chem 75: 5760-5763.

PALMISANO G, DANIELI B, LESMA G AND RIVA R. 1985. Bis(indole) alkaloids. A nonbiomimetic approach to the blue pigment trichotomine dimethyl ester. J Org Chem 50: 3322-3325.

PENG C, CHENG J AND WANG J. 2007. Palladiumcatalyzed cross-coupling of aryl or vinyl iodides with ethyl diazoacetate. J Am Chem Soc 129: 8708-8709.

PETTIT GR AND NELSON PS. 1986. Synthesis of azotomycin synthesis of antineoplastic agents 114. J Org Chem 51: 1282-1286.

PINHO VD AND BURTOLOSO ACB. 2011. Preparation of $\alpha, \beta$-unsaturated diazoketones employing a HornerWadsworth-Emmons Reagent. J Org Chem 76: 289-292.

PINHO VD, GUTMANN B AND KAPPE CO. 2014b. Continuous flow synthesis of $\beta$-amino acids from $\alpha$-amino acids via Arndt-Eistert homologation. RSC Adv 4: 3741937422 .

PINHO VD, GUTMANN B, MIRANDA LSM, DE SOUZA ROMA AND KAPPE CO. 2014a. Continuous flow synthesis of $\alpha$-halo ketones: essential building blocks of antiretroviral agents. J Org Chem 79: 1555-1562.

POLLET P, COPE ED, KASSNER MK, CHARNEY R, TERETT SH, RICHMAN KW, DUBAY W, STRINGER J, ECKERT CA AND LIOTTA CL. 2009. Production of (S)-1-benzyl-3-diazo-2-oxopropylcarbamic acid tertbutyl ester, a diazoketone pharmaceutical intermediate, employing a small scale continuous reactor. Ind Eng Chem Res 48: 7032-7036.

POLYZOS A, O'BRIEN M, PETERSEN TP, BAXENDALE IR AND LEY SV. 2011. The continuous-flow synthesis of carboxylic acids using $\mathrm{CO}_{2}$ in a tube-in-tube gas permeable membrane reactor. Angew Chem Int Ed 50: 1190-1193.

QIAN Y, SHANAHAN CS AND DOYLE MP. 2013. Templated carbene metathesis reactions from the modular assembly of enol-diazo compounds and propargyl acetates. Eur J Org Chem 2013: 6032-6037.

RAMACHARY DB, NARAYANA VV AND RAMAKUMAR K. 2008. Direct ionic liquid promoted organocatalyzed diazo-transfer reactions: diversity-oriented synthesis of diazo-compounds. Tetrahedron Lett 49: 2704-2709.

REGITZ M. 1964. Reaktionen aktiver methylenverbindungen mit aziden, I. Eine neue synthese für a-diazo-bdicarbonylverbindungen aus benzolsulfonylaziden und b-diketonen. Justus Liebigs Ann Chem 676: 101-109.

REGITZ M. 1966. Synthese von diacyl-diazomethanen durch diazogruppenübertragung. Chem Ber 99: 3128-3147.

REGITZ M. 1967. New methods of preparative organic chemistry, transfer of diazo groups. Angew Chem Int Ed Engl 6: 733-749.

REGITZ M. 1972. Recent synthetic methods in diazo chemistry. Synthesis, p. 351-373. 
REGITZ M AND HECK G. 1964. Synthesen und einige umsetzungen des 2-diazo- und des 2-hydroxyindandions-(1.3). Chem Ber 97: 1482-1501.

REGITZ M, HOCKER J AND LIEDHEGENER A. 1973. t-Butyl diazoacetate. Org Synth 5: 179-183.

REGITZ M AND MAAS G. 1986. Diazo compounds: properties and synthesis, Academic Press: Orlando, FL, $608 \mathrm{p}$.

REGITZ M AND MENZ F. 1968. Entformylierende diazogruppen-übertragung - ein neuer weg zu $\alpha$-diazoketonen - aldehyden und carbonsäureestern. Chem Ber 101: 2622-2632.

REGITZ M, MENZ F AND LIEDHEGENER A. 1970. Synthese $\alpha, \beta$-ungesättigter diazoketone durch entformylierende diazogruppen-übertragung. Justus Liebigs Ann Chem 739: 174-184.

REGITZ M, MENZ F AND LIEDHEGENER A. 1971. 2-Diazocycloalkanones: 2-diazocyclohexanone. Org Synth 51: 86-89.

REGITZ M, MENZ F AND RÜTER J. 1967. Synthese von $\alpha$-diazo-carbonylverbindungen durch entformylierend diazogruppenübertragung. Tetrahedron Lett 739-742.

REGITZ M AND RÜTER J. 1968. Synthese von 2-oxo-1diazo-cycloalkanen durch entformylierende diazogruppenübertragung. Chem Ber 101: 1263-1270.

REIDER PJ AND GRABOWSKI EJJ. 1982. Total synthesis of thienamycin: a new approach from aspartic acid. Tetrahedron Lett 23: 2293-2296.

REIDER PJ, RAYFORD R AND GRABOWSKI EJJ. 1982. Synthetic approaches to thienamycin: carbon-carbon bond formation at C-4 of azetidin-2-ones. Tetrahedron Lett 23: 379-382.

RIANELLI RS, DA SILVA FC, DE SOUZA MCBV AND FERREIRA VF. 2006. Mild procedure for preparing vinyldiazoacetic acid esters of carbohydrate acetonides. Lett Org Chem 3: 73-77.

ROSENQUIST NR AND CHAPMAN OL. 1976. A general method for the synthesis of reactive $\alpha, \beta$-unsaturated diazomethyl ketones: allenyl diazomethyl ketone and vinyl diazomethyl ketone. J Org Chem 41: 3326-3327.

ROSSET IG AND BURTOLOSO ACB. 2013. Preparation of $Z$ - $\alpha, \beta$-unsaturated diazoketones from aldehydes. Application in the construction of substituted dihydropyridin-3-ones. J Org Chem 78: 9464-9470.

ROSSET IG, DIAS RMP, PINHO VD AND BURTOLOSO ACB. 2014. Three-step synthesis of $( \pm)$-preussin from decanal. J Org Chem 79: 6748-6753.

ROSSI E, WOEHL P AND MAGGINI M. 2012. Scalable in situ diazomethane generation in continuous-flow reactors. Org Process Res Dev 16: 1146-1149.

SANTIAGO JV. 2015. p-Toluenesulfonyl azide. Synlett 26: 2323-2324.
SARAIREH IAM. 2012. Synthesis and characterization of chiral di(N-protected- $\alpha$-amino)diazo- $\beta$-diketones from $\alpha$-diazoketones and imidazolides derived from amino acids. Tetrahedron Lett 53: 2023-2025.

SCHNAARS C, HENNUM M AND BONGE-HANSEN T. 2013. Nucleophilic halogenations of diazo compounds, a complementary principle for the synthesis of halodiazo compounds: experimental and theoretical studies. J Org Chem 78: 7488-7497.

SCHÖLLKOPF U, BÁNHIDAI B, FRASNELLI H, MEYER R AND BECKHAUS H. 1974. $\alpha$-Diazo- $\beta$ hydroxy-carbonsäureester und -ketone aus carbonylund diazolithioverbindungen sowie ihre umlagerung $\mathrm{zu}$ $\beta$-ketocarbonsäureestern und $\beta$-diketonen. Liebegs Ann Chem, p. 1767-1783.

SCHÖLLKOPF U, GERHART F, REETZ M, FRASNELLI H AND SCHUMACHER H. 1968. Halogendiazoessigsäureäthylester aus quecksilber-bis-diazoessigsäureäthylester. Liebegs Ann Chem 716: 204-206.

SCHÖLLKOPF U AND RIEBER N. 1969. C-alkylierung von silber-diazoessigsäureäthylester und silber-diazoketonen mit Sn1-aktiven halogeniden. Chem Ber 102: 488-493.

SCHÖLLKOPF U, TONNE P, SCHÄFER H AND MARKUSH P. 1969. Synthesen von nitrodiazoessigsäureestern, nitro-cyan und nitro-trifluormethyldiazomethan. Liebegs Ann Chem 722: 45-51.

SCHROEN M AND BRASE S. 2005. Polymer-bound diazonium salts for the synthesis of diazoacetic esters. Tetrahedron 61: 12186-12192.

SHI WF, MA M AND WANG JB. 2004. An efficient and mild preparation of vinyl diazo carbonyl compounds. Chin Chem Lett 15: 911-914.

SHIOIRI T, AOYAMA T AND MORI S. 1990. Trimethylsilyldiazomethane. Org Synth 68: 1-7.

SICILIANO C, DE MARCO R, GUIDI LE, SPINELLA M AND LIGUORI A. 2012. A one-pot procedure for the preparation of $N$-9-Fluorenylmethyloxycarbonyl- $\alpha$-amino diazoketones from $\alpha$-Amino Acids. J Org Chem 77: 10575-10582.

SIGMA-ALDRICH CO LLC. 2007. Diazald ${ }^{\circledR}$ and Diazomethane generators. Technical Information Bulletin No. AL-180. Available at: http://www.sigmaaldrich.com/ etc/medialib/docs/Aldrich/Bulletin/al_techbull_al180. Par.0001.File.tmp/al_techbull_al180.pdf. Accessed on July 17, 2017.

STRUEMPEL M, ONDRUSCHKA B, DAUTE R AND STARK A. 2008. Making diazomethane accessible for R\&D and industry: generation and direct conversion in a continuous micro-reactor set-up. Green Chem 10: 41-43.

TABER DF, GLEAVE DM, HERR RJ, MOODY K AND HENNESSY MJ. 1995. A new method for the construction of $\alpha$-diazoketones. J Org Chem 60: 2283-2285. 
TABER DF AND HOERRNER RS. 1992. Enantioselective Rh-mediated synthesis of (-)-PGE2 methyl ester. J Org Chem 57: 441-447.

TABER DF, RUCKLE JR RE AND HENNESSY MJ. 1986. Mesyl azide: a superior reagent for diazo transfer. J Org Chem 51: 4077-4078.

TABER DF, SHETH RB AND JOSHI PV. 2005. Simple preparation of $\alpha$-diazo esters. J Org Chem 70: 2851-2854.

TALERO AG AND BURTOLOSO ACB. 2017. Sharpless asymmetric dihydroxylation on $\alpha, \beta$-unsaturated diazoketones: a new entry for the synthesis of disubstituted furanones. Synlett 28: 1748-1752.

TARRANT E, O'BRIEN CV AND COLLINS SG. 2016. Studies towards a greener diazo transfer methodology. RSC Adv 6: 31202-31209.

TINOCO A, STECK V, TYAGI V AND FASAN R. 2017. Highly diastereo- and enantioselective synthesis of trifluoromethyl- substituted cyclopropanes via myoglobincatalyzed transfer of trifluoromethylcarbene. J Am Chem Soc 139: 5293-5296.

TOMA T, SHIMOKAWA J AND FUKUYAMA T. 2007. $N, N^{\prime}$ Ditosylhydrazine: a convenient reagent for facile synthesis of diazoacetates. Org Lett 9: 3195-3197.

TROST BM, MALHOTRA S AND FRIED BA. 2009. Magnesium-catalyzed asymmetric direct aldol addition of ethyl diazoacetate to aromatic, aliphatic, and $\alpha, \beta$ unsaturated aldehydes. J Am Chem Soc 131: 1674-1675.

TROST BM, MALHOTRA S, KOSCHKER P AND ELLERBROCK P. 2012. Development of the enantioselective addition of ethyl diazoacetate to aldehydes: asymmetric synthesis of 1,2-diols. J Am Chem Soc 134: 2075-2084.

TRUONG P, SHANAHAN CS AND DOYLE MP. 2012. Divergent stereocontrol of acid catalyzed intramolecular Aldol reactions of 2,3,7-triketoesters: synthesis of highly functionalized cyclopentanones. Org Lett 14: 3608-3611.

URAGUCHI D, SORIMACHI K AND TERADA M. 2005. Organocatalytic asymmetric direct alkylation of $\alpha$-diazoester via $\mathrm{C}-\mathrm{H}$ bond cleavage. J Am Chem Soc 127: 9360-9361.

WEYGAND F, BESTMANN H AND KLIEGER E. 1958. Synthese des 6-diazo-5-oxo-L-norleucins und der 7-diazo6-oxo-2-L-amino-önanthsäure. Chem Ber 91: 1037-1040.

WILDS AL AND MEADER AL. 1948. The use of higher diazohydrocarbons in the Arndt-Eistert Synthesis. J Org Chem 13: 763-779.

WOTIZ JH AND BUCO SN. 1955. The Arnt-Eistert synthesis of unsaturated acids. J Org Chem 20: 210-214.

XIAO F, LIU Y AND WANG J. 2007. DBU-catalyzed condensation of acyldiazomethanes to aldehydes in water and a new approach to ethyl $\beta$-hydroxy $\alpha$-arylacrylates. Tetrahedron Lett 48: 1147-1149.
XU X, QIAN Y, ZAVALIJ PY AND DOYLE MP. 2013. Highly selective catalyst-dependent competitive 1,2$\mathrm{C} \rightarrow \mathrm{C},-\mathrm{O} \rightarrow \mathrm{C}$, and $-\mathrm{N} \rightarrow \mathrm{C}$ migrations from $\beta$-methylene$\beta$-silyloxy- $\beta$-amido- $\alpha$-diazoacetates. J Am Chem Soc 135: 1244-1247.

XU X, RATNIKOV MO, ZAVALIJ PY AND DOYLE MP. 2011. Multifunctionalized 3-hydroxypyrroles in a threestep, one-pot cascade process from methyl 3-TBSO-2diazo-3-butenoate and nitrones. Org Lett 13: 6122-6125.

XU X, ZAVALIJ PY AND DOYLE MP. 2012. Synthesis of tetrahydropyridazines by a metal-carbene-directed enantioselective vinylogous $\mathrm{N}-\mathrm{H}$ insertion/lewis acidcatalyzed diastereoselective Mannich addition. Angew Chem Int Ed 51: 9829-9833.

YAO W AND WANG J. 2003. Direct catalytic asymmetric Aldol-type reaction of aldehydes with ethyl diazoacetate. Org Lett 5: 1527-1530.

YATES P, GARNEAU FX AND LOKENSGARD JP. 1975. Preparation and spectra of mercuribis ( $\alpha$-diazo ketones). Tetrahedron 31: 1979-1983.

YE H ET AL. 2013. A safe and facile route to imidazole-1sulfonyl azide as a diazotransfer reagent. Org Lett 15: 1821.

YE T AND MCKERVEY MA. 1992. Synthesis of chiral $N$-protected $\alpha$-amino- $\beta$-diketones from $\alpha$-diazoketones derived from natural amino acids. Tetrahedron 48: 80078022.

YE T AND MCKERVEY MA. 1994. Organic synthesis with $\alpha$-diazo carbonyl compounds. Chem Rev 94: 1091-1160.

ZHANG J, CHEN W, HUANG D, ZENG X, WANG X AND HU Y. 2017. A tandem synthesis of $\alpha$-diazoketones from 1,3-diketones. J Org Chem 82: 9171-9174.

ZHANG Y AND WANG J. 2009. Recent development of reactions with a-diazocarbonyl compounds as nucleophiles. Chem Commun 36: 5350-5361.

ZHAO Y, JIANG N, CHEN S, PENG C, ZHANG X, ZOU Y, ZHANG S AND WANG J. 2005. Concise and diastereoselective approach to syn and anti-N-tosyl- $\alpha$ hydroxy $\beta$-amino acid derivatives. Tetrahedron 61: 65466552.

ZHAO Y, MA Z, ZHANG X, ZOU Y, JIN X AND WANG J. 2004. A highly stereoselective addition of the anion derived from $\alpha$-diazoacetamide to aromatic $\mathrm{N}$-tosylimines. Angew Chem Int Ed 43: 5977-5980.

ZHAO Y AND WANG J. 2005. Nucleophilic addition to $\mathrm{C}=\mathrm{O}$ and $\mathrm{C}=\mathrm{N}$ bonds by nucleophiles containing a diazo group. Synlett 19: 2886-2892.

ZHOU L AND DOYLE MP. 2010. Stereoselective synthesis of highly functionalized $\alpha$-Diazo- $\beta$-ketoalkanoates via catalytic one-pot Mukaiyama-Aldol reactions. Org Lett 12: 796-799. 